\title{
Can Zero-Coupon Bond Yield Curve Predict Economic Growth? - The Case of China
}

\author{
Chanaphon Sakkapalangkul \\ SILC Business school, Shanghai University, 266 Ju Feng Yuan Street, Baoshan, Shanghai 201900, China
}

\begin{abstract}
Since China's economic reform in 1978, the country's economic system has foreseen rapid evolvements, particularly in issuing debt securities by the Chinese central government to financing its drastic economic growth (Loo \& Lqbal, 2019). This research study examines the zero-coupon bond yield curve's predictive power on China's GDP growth rate by adopting the Nelson-Siegel (1987) dynamic yield curve model. This research study adopts various approaches to refining the Nelson-Siegel (1987) model to enhance its predictive power on future economic activities, drawing upon the modifications undertaken by Diebold \& Li's (2006) study to examining the constructed yield curve in accordance with the three latent factors of level, slope and curvature of the entire yield curve. A 67 period of zero-coupon bond yields is gathered between Q3 2002 and Q1 2019 quarterly from zerocoupon bond maturities of $1,3,5,10,20$, and 30 years, finding that all types of zero-coupon bond maturities to exhibit similar yield curve movements across short, intermediary and long term durations. A multiple regression model was used to examine the correlation coefficient between the three latent factors and China's GDP, finding a significant relationship in the slope factor. A relationship was also found between the level and slope factors with a significance of 0.854 , whereby the average rates between the two variables were calculated under the augmented Dicky Fuller test to ensure all factors are at stationary states to enhance the accuracy of future testing. The researcher also performed a least-squares equation (OLS) test to addressing the identified multicollinearity problem aforementioned, finding the R-squared value of $29.6 \%$. Which suggested the level and curvature factors of the constructed yield curve would accurately explain $29.6 \%$ of China's GDP growth rates. To further examine the predictive power of the constructed yield curve in accordance to Nelson-Siegel's (1987) dynamic model, an out-of-sample forecasting method is employed with the out-of-sample size of 40 periods between Q3 2002 and Q2 2012 against 27 periods between Q3 and Q1 2019. The out-of-sample regression test founded an R squared value of 11.4,\% suggesting that in sample forecasts contained higher predictive power to China's GDP growth based on the constructed yield curve. Furthermore, the out-of-sample forecast results show no significant relationship between the level and curvature factors, further reaffirming the argument that the yield curve in sample forecasts would better predict future economic activities. The research findings were consistent with findings from other studies conducted by Diebold \& Li (2006); Hvozdenska (2015), and Campbell \& Thompson (2008), whereby the spread of the yield curve constructed by the Nelson-Siegel (1987) dynamic model showed a strong relationship between China's GDP growth and the produced yield curve, representing strong predictive power and offers valuable insights to addressing the identified research gap where minimal research studies have explored the predictive power of China's zero-coupon bond yields in relation to the macroeconomic outlook.
\end{abstract}

Keywords: Nelson-Siegel model, Yield curve, Zero-coupon bond, Maturity, Regression, Dynamic model.

DOI: $10.7176 / \mathrm{JEP} / 11-24-02$

Publication date: December $31^{\text {st }} 2020$

\section{Introduction}

The Chinese economy has experienced substantial growth since the country's economic reform in 1978, opening up the traditionally state-owned economic environment with the introduction of a series of new economic policies to encourage and stimulate foreign direct investments and exports from domestic firms $(\mathrm{Li}, 1998)$. Throughout the early phases of the economic reform, It reduced trade barriers for foreign firms by $41 \%$ as many multinational corporations entered the Chinese market, resulting in a drastic drop in state ownership of industries as industrial output from state-owned companies reduced by 66\% between 1980 and 2005 (Bai et al, 2006). Between 19802010 , the growth of investments and net exports was faster than the growth of consumption, and the proportion of investments and net exports to GDP was higher than the percentage of expenditure (Bai et al, 2006). However, external demand has experienced steady declines as domestic overcapacity has continued to draw significant academic attention, voicing the concerns over the slowing growth of the Chinese economy in recent years in comparison to the early phases of the economic reform era (Lardy, 2019). This current state of affairs is widely regarded as the 'new normal' for the Chinese economy, particularly concerning domestic demand and consumption in the rapidly evolving macroeconomic environment of China (Jiang et al, 2017). This is particularly evident over recent years as Jiang et al (2017) argue that the static selection of dominant predictors to forecasting China's GDP growth no longer captures and represents the rapidly changing Chinese market's dynamic characteristics. On the other hand, as the second largest economy worldwide, the key determinant factors to China's GDP growth are complicated by a wide range of new and changing macroeconomic and financial variables. This implies the need 
for a sophisticated forecasting model that integrates mixed-frequency data across multiple variables in a longitudinal approach (Jiang et al, 2017).

Drawing upon the above considerations, it is apparent that the capability to accurately forecasting China's GDP growth requires the analysis of a variety of dynamic factors. Taking into account macroeconomic forecasts, GDP growth trends, and yield curves have found to represent a highly complex and challenging task for the Chinese national government to execute with high accuracy (Lu et al, 2018). Moreover, GDP growth forecasts have assumed heightened importance for the Chinese government. China represents the only major economy to set rigid targets for annual GDP growth rates with GDP management plans to meet and exceed GDP growth targets amongst other major economies (Lyu et al, 2018). A large body of empirical studies has conducted to exploring and implementing various econometric methods to forecasting and predicting GDP growth. It is commonly conducted by analyzing the yield curve from treasuries to reflect the changes from economic activities, interest and inflation rates, which helps to predict the nature of future GDP rates (Diebold et al, 2008; Coroneo et al, 2011; Fernandes \& Vieira, 2019). Nelson-Siegel's (1987) economic modeling of yield curve approach has been widely applied in academic studies and by central banks to predicting GDP growth based on the yield curve of zerocoupon bonds. Combining three distinctive factors that include the level, slope, and curvature, these factors are used to estimate the term structure of interest rates and predicting future economic changes (GDP growth/ declines). According to Nelson \& Sigel (1987), the level factor (long-term yield-to-maturity) is closely linked to inflation expectations. Whereby the steepness of the slope factor (the long-term yield-to-maturity minus the short-term yield-to-maturity) has been shown to vary according to different stages of the business cycle. The predictive power of the yield spread for GDP growth has also been tested and proven when forecasting future economic changes. Substantial empirical evidence is shown in support of the yield spread's capacity to forecast GDP growth. The yield spread ranks among the most popular options for predicting the future path of economic activity and will represent the focal interest of this research study.

\subsection{Background on China's GDP}

The economic system of China has transitioned from a centrally-planned system to a more market-oriented system under the movement defined by Naughton (2008) as the political-economic transition of China. As of 2019, China is ranked as the world's second-largest economy through nominal GDP and of 2017 the greatest in the world by way of purchasing power parity, taking upon the role as the world's fastest-growing foremost economy, with growth rates averaging 6\% over 30 years (Piketty et al, 2019). According to Wen \& Wu (2019), China's non-public region accounted for $60 \%$ of the GDP in 2018. China has lots of natural resources with an estimated worth of $\$ 23$ trillion, $90 \%$ of which are coal and exotic earth metals. China also has the world's biggest complete banking sector property of approximately $\$ 40$ trillion (268.76 trillion China currency), with $\$ 27.39$ trillion in total deposits (Wen $\& \mathrm{Wu}, 2019)$. It has the fourth-largest inward overseas direct investment and the eleventh-largest outward foreign direct investment. China has the world's second-highest variety of billionaires, with a total wealth of \$996 billion (Xiao, 2019). Of the world's five hundred biggest companies, 129 headquartered in China. It has the world's biggest foreign-exchange reserves worth $\$ 3.1$ trillion. Historically, China was one of the world's predominant financial powers for most of the two millennia from the 1st until the 19th century. China is the world's greatest manufacturing economic system and the exporter of goods (Xiao, 2019). It is also the world's fastest-growing customer market and second-largest importer of goods. China is a net importer of offerings products. It is the greatest buying and selling state globally and performs a prominent function in international trade, and has an increasing number of engaged in change agencies and treaties in recent years. China's increasing integration with expanding inward and outward economic activities have further driven international trade, becoming a member of the World Trade Organization in 2001 (Rumbaugh \& Blancher, 2004).

Additionally, China has free trade agreements with many countries worldwide, which include ASEAN, Australia, New Zealand, Pakistan, South Korea, and Switzerland (Cai, 2003). The provinces in the coastal areas of China tend to be greater industrialized, while areas in the hinterland are less developed. As China's economic significance has grown, so has attention to the structure and fitness of the economy. China's largest trading friends are the US, E.U., Japan, Hong Kong, South Korea, India, Taiwan, Australia, Vietnam, Malaysia, and Brazil (Cai, 2003). The Shanghai Stock Exchange accounts for one of the world's biggest inventory exchanges by way of market capitalization and exchange volume. With 783 million workers, Chinese labour pressure is the world's greatest from the year 2019 (Ali et al, 2020). China ranks 31st on the ease of commercial enterprise index and 28th on the Global Competitiveness Report (Loo \& Lqbal, 2019). To minimalize the socioeconomic cost of environmental pollution in China, China has often been advised by reputable industry experts such as Nicholas and Fergus Green of the Grantham Research university of Climate Change. As a result, the environment that the economic system of China shifted to greater superior industrial development with low carbon dioxide emissions and a higher allocation of countrywide resources to innovation (Wang et al, 2020). Furthermore, R\&D for a sustainable monetary boom to reduce the impact of China's heavy industry. Under the planning goals of the Chinese central government, the communist party standard secretary Xi Jinping's Chinese dream, described as 
reaching the $100 \mathrm{~s}$, can be called the material aim of China becoming a "moderately well-off society" by way of 2021. China's modernization intention turned into a thoroughly developed nation with the aid of 2049, the one centesimal anniversary of the founding of the People's Republic (Wang et al, 2020).

The Chinese economy's internationalization will affect the standardized economic forecast officially launched in China via the Purchasing Managers Index in 2005 (Wei et al, 2005). As China's financial system grows, so does China's national currency, the Renminbi, which undergoes the procedure wished for its internationalization. China launched the founding of the Asian Infrastructure Investment Bank in 2015. The monetary improvement of Shenzhen has induced the city to refer to as the world's next Silicon Valley. From the year 2017, 109 of the Fortune Global five hundred organizations base in China. In recent years, government-claimed increase numbers have come under elevated scrutiny, as each native and overseas monetary and monetary observers, as properly as Chinese authorities declare that the authorities have been overstating its economic output (Yu, 2017). Examples encompass the provincial government in Liaoning publicly admitting that the government had been overstating GDP by $20 \%$ when publishing its financial resources from 2011 to 2014. the amount of Tianjin in trillion-yuan GDP claim for 2016 was, in fact, a 1/3 lower, at 665 billion yuan ( $\$ 103$ billion) (Yu, 2017). Some analysts consider China's legitimate figures for the GDP boom inflated utilizing at least 50\%. A Wall Street Journal survey of sixtyfour pick out western economists determined that 96 percent of respondents at China's GDP estimates do not "accurately reflect the kingdom of the Chinese economy" (Hong \& Xianyu, 2011, p85). However, a paper via the National Bureau of Economic Research in 2017 argued on the contrary direction regarding the credibility of important data. The article lists China's province-level divisions by the GDP. For GDP of each province that listed in both the national forex Renminbi (RMB) and at nominal U.S. dollar values according to annual average alternate charges, as historical figures and rankings are also given for major years since the 1978 economic reform (Chen et al, 2019).

The financial reforms since 1978 helped to propel China into the ranks of the world's primary monetary powers. To guide financial development, the Chinese central government adopts "five-year plans" that element its financial priorities and fundamental policies (Aglietta \& Bai, 2016). The Thirteenth Five-Year Plan (2016-2020) is presently carried out. Like in Japan and South Korea, China has grown steadily, elevating the earnings ranges and dwelling requirements of its citizens while producing items that fed. From 1978 to 2005, China's GDP per capita grew from $\$ 153$ to $\$ 1,284$. Its cutting-edge account surplus multiplied extra than twenty times between 1982 and 2004, from 5.7 billion U.S. dollars to 71 billion U.S. dollars (Aglietta \& Bai, 2016). In the period, China also became an industrial powerhouse, moving beyond initial successes in low-wage sectors like clothing and shoes to the increasingly state-of-the-art production of computers, pharmaceuticals, and automobiles. However, it remains doubtful how long the Chinese financial system can maintain this trajectory. According to the eleventh five-year plan, China needed to maintain an annual boom rate of $8 \%$ for the foreseeable future $(\mathrm{Ng}$ et al, 2016). Only with such tiers of growth, the management argued, should China proceed to advance its industrial prowess, raise its citizen's trendy of living, and redress the inequalities that were cropping up throughout the nation. Regardless, no country had ever before maintained the sort of boom that China used to be predicting. Moreover, China had, to some extent, already gone through the less difficult components of development ( $\mathrm{Ng}$ et al, 2016). In the 1980s, it had modified its large and inefficient agricultural sector, liberating its peasants from central planning and winning them to the motive of reform. In the 1990s, China began to increasingly reorganize its stagnant industrial sector and foreign traders for the first time. Subsequently, new insurance policies had catalyzed the country's extraordinary special growth (Lardy, 1995).

Instead, China had to take what many considered as the ultimate step toward the market, liberalizing the banking area and launching the beginnings of an actual capital market. According to an article in the Journal of the Asia Pacific Economy by Feridun of University and Abdul Jalil from Wuhan University in China, financial development is driven by the reduction in financial inequality in China (Jalil \& Feridun, 2011). This process, however, would not come without challenges. As of 2004, China's state-owned corporations were nevertheless only partly reorganized, and its banks have been coping with the burden of over 205 billion U.S. dollars (1.7 trillion RMB) in non-performing loans. These monies had little hazard of ever being repaid, and the use of a had a floating change rate, strict controls on each the present day, and capital accounts (Jalil \& Feridun, 2011). Chinese provinces and cities have long suspected of "cooking" their numbers, with the focal point on nearby government officials. Their overall performance often assesses based totally on how well their respective economies have performed (Firth et al, 2011). In recent years, China claimed growth numbers have come underneath accelerated scrutiny, with both non-Chinese financial and financial observers as nicely as Chinese authorities claimed, the authorities have often been accused of inflating its monetary output. Instances of falsified financial statements officially gathered public scrutiny when Binhai New Area in the northern Chinese Tianjin saw that Tianjin's trillion yuan GDP claim was $1 / 3$ lesser, at 665 billion yuan, which is around \$103 billion (Liao et al, 2017). Inner Mongolia's government also showed that about $40 \%$ of the region's said industrial output in 2016 , as well as $26 \%$ of mentioned fiscal revenues, did no longer exist. The provincial government in Liaoning publicly confessed that the government has been cooking the books when publishing its financial records from 2011 to 2014. Liaoning, frequently referred 
to as China's rust belt admitted in 2017 that neighborhood GDP numbers from 2011 to 2014 had been inflated artificially with the aid of about $20 \%$ (Liao et al, 2017).

Regarding the credibility, a team of Bloomberg (2017) economists wrote: "We do not have complete selfassurance in the numbers, and we are surprised through the acceleration in offerings output given the crumple in the equity market." A Wall Street Journal survey of sixty-four pick out economists observed that $96 \%$ of respondents think China's GDP estimates do not "accurately replicate the country of the Chinese economy." According to Zhang (2019), Chinese officers probably "overstate GDP by using about two to three percentage points." Chinese premier Li Keqiang shows he is a ways from assured in the country's GDP estimates, calling them "man-made" and unreliable, in accordance to a leaked record from 2007 acquired via WikiLeaks. He said government statistics releases, particularly the GDP numbers, ought to be used "for reference only." The Li Keqiang index is an alternative size of Chinese financial performance that makes use of three variables Li preferred. Light pollution is data, immune to an error that some analysts use to model the Chinese growth (Song \& He, 2015). Economic analyst Shilling (2016) suggests that China's respectable figures are off by as an awful lot as $50 \%$. He calculates an actual growth rate of 3.5 percent instead of seven percent. Other analysts like Li et al (2020) agree with this assessment and estimate a boom rate at around 4\% or less. According to a lookup from the Brookings Institution, China's economic increase can also have been over via two percentages between 2008 and 2016, which means that the authorities can also have been overestimating the measurement of the Chinese economic system by using sixteen percent in 2016. In 1985, the State Council of China passed to establish a System of National Accounting, use the gross home product (GDP) to measure the countrywide economy (Harms \& Steiner, 2019). Therefore, sufficient academic and practitioner challenges that the central Chinese government's published GDP growth rates to lack credibility and accuracy. There are suggestions that the need for econometric modeling approaches is to better measure and forecast China's real GDP movements as the following section will aim to discuss critically.

\subsection{Research rationale}

To contribute to the research field and address the current research gap where a lack of academic studies have been conducted to applying yield curve models in predicting GDP growth in China since its economic reform in 1978. This paper adopts the dynamic version of the Nelson-Siegel (1987) yield curve model proposed by Diebold \& Li (2006), determining the accuracy in the predictive power of the yield spread across the entire yield curve in relation to real economic output changes to accommodate the dynamic characteristics of the Chinese economic environment. Nelson-Siegel's (1987) model is chosen over other yields curve models such as Svensson's (1994) NSS model and the Marsh \& Cormier's (2002) spline model. It is due to its proven excellent out-of-sample forecasting performance for future yield, prioritizing on the three latent dimensions offered by the model to neglect other lesser relevant factors. This paper further expands on Diebod \& Li's (2006) application of the Nelson-Siegel (1987) model to explain the entire term structure of interest rates by interpreting the level, slope and curvature levels of the yield curve from zero-coupon bonds. This paper is building on this application with an analysis of whether an in-sample of out-of-sample fit would better predict the future economic output (GDP) changes. In the case of predicting future economic outputs, the dynamic Nelson-Siegel (1987) model has two distinct advantages over the traditional term spread framework. Firstly, the model utilizes information over the entire term structure of interest rates. Secondly, the real GDP growth can be modelled together with yields in accordance with three endogenous factors that define the yield curve. The focal analysis of this paper examines whether GDP growth forecasts can be predicted and improved by using information from the entire yield curve, as opposed to a term spread used in a traditional forecasting term spread model. In this paper, the research performs an out-of-sample forecast comparison for China's GDP growth that is explained by different yield factors.

According to Ang et al (2006), the conduct of the yield curve illustrates the adjustments in bond yield changes throughout the bond maturity duration. In times of economic recessions, premia on long-term bonds tend to be high, and yields on quick bonds tend to be lower (Ang et al, 2006). In Cochrane \& Piazzesi's (2009) study, in the event of sloping yield curves with an upward bend, premia on long relationships are found to be countercyclical because buyers are lesser encouraged to invest due to high economic uncertainty. In stark contrast, yields on short bonds tend to be procyclical due to the fact the Federal Reserve tends to lower quick returns in times of economic recessions to stimulate commercial, economic activities. For example, for each two share point decline in GDP growth, the Fed ought to reduce the nominal yield by way of 1 proportion factor following the Taylor (1993) rule. It is evident from historical events such as the 2000 tech bubble burst and the 2008 global financial crisis that economic recessions are generally the aftermath of drastic economic expansions (Chu, 2013). Therefore, China's drastic economic expansion since its economic reform illustrates similar patterns and may represent valuable predictions for a potential recession shortly. The application of the Nelson-Siegel (1987) model to predicting economic growth in China would thus contribute with new research insights to its accuracy and future applications to recognizing potential economic declines. Guided by this vision, many empirical studies have attempted to predict GDP growth via OLS regressions applied on the slope of the yield curve, generally measured as the 
difference between the longest yield and the shortest maturity yield (Ang et al, 2006; Chinn \& Kucko, 2010; Cochrane \& Piazzesi, 2010).

As founded in Cochrane \& Piazzesi's (2010) study, the higher the upward slope (hill) or period spread is likely to predict GDP increases in the future. Whereby other studies conducted by Abdymomunov (2013) founded that the identical measures of slopes would likely to predict actual rates. A research consensus is established over the high predictability of economic recessions upon the flattening of the yield curve from a positive upward slope, as evidential in Goodhart's (2008) study from the 2007-2008 global financial crisis. The application of discrete choice models showcases a recession code as one and other times systems as zeros, representing a vital variable in the construction of the central business cycle indicator index. Despite several critiques over the instability to predicting future economic growth/ decline from yield curve trends (Dale, 2012; Watkins, 1997; Bluwsein et al, 2020), a wide body of empirical studies have been conducted with positive accuracy to predicting GDP growth from yield curves (Goodhart, 2008; Ang et al, 2006; Cochrane \& Piazzesi, 2010). Therefore, this research aims to explore further the accuracy of predicting economic growth from the yield curve of zero-coupon bonds, given the resulted success from many empirical studies and the established relationship between yield curves and motivation to engage in financial/ investment activities which would directly influence economic growth. Furthermore, the research argues that there are significant research values from studying the yield curve via explicit modelling of its collective dynamics with GDP growth. The adopted dynamic model additionally policies out arbitrage possibilities between bonds of exceptional maturities and, as a consequence, imposes a new structure than the unrestricted OLS regression framework previously used in the literature.

Despite the empirical study, findings suggest that the use of OLS regression methods to having a predictive power for GDP growth rates, this is often criticized for representing an incomplete portrayal of the yield curve and its dynamic relationships with GDP (Chinn \& Kucko, 2010). Therefore, the researcher anticipates and recognizes that a complete yield curve would include the arbitrary maturity used in the building of the time spread, thus enhancing the predictive power of GDP growth as founded in Chinn \& Kucko's (2010) study. The researcher intends to use this information across the entire yield curve as an alternative rather than merely the lengthy maturity segment, thus resulting in greater accuracy in predictability and correcting apparent outlying errors in the forecasts for GDP. In an OLS framework, on account that yields of different maturities are particularly cross-correlated, it is difficult to use more than one return as regressors due to collinearity problems as mentioned by Gilli et al (2010). This collinearity problem suggests that the condense of information contained in many yields are driven down in quantity. Therefore, the researcher adopts a more stable approach to representing the GDP forecasts across exceptional horizons to unique components of the yield curve. Through OLS's application, this research conducts a sophisticated analysis by utilizing a combination of regressions approaches that offer valuable insights on their relationship and intended values with each other. Moreover, OLS's application would help improve the out-ofsample forecast accuracy in predicting real GDP growth as founded in Azamat's (2013) study. Other empirical studies have proposed varying explanations to the relationship between the nature of yield curves and subsequent future economic activities, based on the ideas from Harvey's (1989) study that smoothing intertemporal consumptions and the actual term structure of interest rates. Furthermore, empirical studies agree that investors have the incentive to store in the present day duration by way of promoting permanent property and the investments on bonds, anticipating the gains from maturity payments, particularly in poorly performing economic periods (Haubrich \& Dombrosky, 1999; Ang et al, 2006). This will lower the yields for the bond relationships that will mature in the future, illustrating a predictive relationship between yield curves and future monetary growth.

\subsection{Research aims and objectives}

This research aims to examine the predictive power of the zero-coupon bond yield curve on China's GDP growth rate with the adoption of the Nelson-Siegel (1987) dynamic yield curve model, drawing upon the predictive power of the three latent factors proposed by the model under the level, scope and curvature dimensions. This research applies multiple regression approaches to explore the relationship between the three latent factors and their predictability on China's GDP growth rates. Furthermore, to improve and testify the predictive power of the Nelson-Siegel (1987) model on China's GDP growth rates, an out-of-sample forecast analysis is conducted in comparison to in-sample forecasts, revealing the influence of short, medium, and long term interest rates on actual GDP growth rates. In order to fulfil the proposed research aims, the following research objectives are accomplished:

- To gather the yield values from the Chinese government's zero-coupon bonds across 67 periods between Q3 2002 and Q1 2019, extracting these values on a quarterly basis for zero-coupon bonds with maturities of 1 year, 3 years, 5 years, 10 years, 20 years, and 30 years.

- $\quad$ To apply the Nelson-Siegel (1987) model under the three latent factors of level, scope, and curvature on the extracted zero-coupon bond yield values to predicting China's economic growth in accordance to the yield curve.

- To perform an OLS regression analysis to analyze the relationship between the three latent factors (independent variables) to predict better the values of China's GDP growth (dependent variable). 
- To perform a multicollinearity regression analysis to explore the correlation between the independent variables further and to identify regression coefficients.

- To compare and contrast in-sample and out-of-sample forecasts to revealing the predictability of future economic growth from 40 in-sample periods and 27 out-of-sample periods.

\subsection{Research contributions}

This research aims to contribute to the academic field and address the identified research gap where a lack of empirical studies has been conducted to measuring the predictive power of the entire zero-coupon yield curve for China's economic output growth (Chang et al, 2019). Despite numerous research studies conducted toward the predictive power of yield curve on future economic activities (Adams \& Deventer, 1994; Loannides, 2003; Bolder \& Gusba, 2002; Tanggard, 1997; Coroneo et al, 2011; Krippner, 2015 and Gilli et al, 2010), the research context of these papers are largely based on western economies, and minimal academic studies have been applied and dedicated to exploring China's GDP growth via yield curve modelling, in spite of the growing importance and influence of China's economy on international and domestic trade (Loo \& Lqbal, 2019). Moreover, many empirical studies examine only certain points of the yield curve, particularly for the short-term yield of treasury bonds rather than the term spread, which is found to indicate considerable predictive power for real GDP growth (Singleton \& Umantsev, 2002; Duffie et al, 2003; Chance, 1990). This adds to the research importance to understanding how the issuing of the country's zero-coupon bonds have affected investor preferences. In particular with the affecting the economic output growth of the country is challenged by many economists to be of highly inflated, regarding the monetary output disclosure in major cities such as the Binhai district in Tianjin in 2017 and Inner Mongolia in 2016, where a 33\% and 26\% difference was found in disclosed and actual GDP growth (Liao et al, 2017). This research aims to contribute to the understanding and to predict of China's economic growth using the NelsonSiegel (1987) model to provide detailed modelling of China's zero-coupon bond yield curve and measuring its effectiveness in forecasting future economic activities. The research aims to use an out-of-sample forecast method which has not yet been applied to China's zero-coupon bond yields in literature. Furthermore, the only academic paper conducted to measure the predictive power of the term structure of bonds for forecasting upcoming economic recessions by Chang et al (2019). Adopted a spline modelling approach of the yield curve lacks sufficient interpretation of latent factors such as level, scope, and curvature for the yield curve as proposed in economic modelling approaches to constructing yield curves.

Therefore, this paper contributes to an economical approach under the Nigel-Siegel (1987) model to evaluate the yield curve's influence and predictive power. These three latent factors incorporate a more sophisticated approach to predicting future economic activities that have not been accomplished in empirical studies when based on Chinese zero-coupon bond yields. An extensive review of empirical literature founded a lack of a unified approach to applying yield curve methods to explaining future economic behaviours (Ang et al, 2006; NymandAnderson, 2018). It is shown by the segmented market theory that focuses on the supply and demand of only one type of debt security (Kidwell \& Koch, 1983; Choudhry, 2008; Van Horne, 1980). This research will cohere to this theory and explore the predictive power of only Chinese zero-coupon bond yields as opposed to combining a range of other debt securities to generate more specific and accurate research findings. Moreover, this research study also incorporates the pure expectation theory as identified to be a common approach to studying yield curves to focus on bonds issued from the same bond issuer. Whereby the theory argues that then investment preferences of investor types across short, intermediate, and long term bonds differ (Haldane, 2000). Therefore, the entire yield curve of the zero-coupon bond issued by the Chinese government between Q3 2002 and Q1 2019 across the maturity range of 1 year up to 30 years is studied and further tested by using out-of-sample forecasts. Overall, the lack of a unified understanding of the understanding and application of yield curve amongst empirical literature to explaining future economic activities is found to be a key research gap. This research study aims to address, particularly in the Chinese research context and toward zero-coupon bonds, which have been mainly neglected in empirical studies. The application of the Nelson-Siegel (1987) dynamic model to forecasting zero-coupon yield curves under the three latent factors would capture the dynamics and unique patterns of zero-coupon yield curve across the entire yield curve. It would also enhance the accuracy to testifying the predictive power of the constructed yield curve to forecasting the future economic activities by comparing in-sample to out-of-sample data sets. Moreover, research findings would contribute to the practitioner field as the predictive power of the zerocoupon yield curve constructed via Nelson-Siegel's (1987) model on China future economic activities. It would also provide valuable insights when predicting potential future economic growth or decline using the same model, which enhance the expectations on short, medium, and, long term interest rate changes. To facilitate more appropriate investment decisions for investors as well as offering a more accurate approach to understanding China's real GDP growth over its highly criticized inflated disclosures from the government.

\section{Research context - Literature review}

This chapter will critically review empirical studies conducted within bond yields, particularly major research 
studies that have adopted the Nelson-Siegel (1987) dynamic model to construct yield models from three latent factors that include level, scope, and curvature. The purpose of this chapter is to explore empirical studies conducted in the relevant research field critically. Moreover, to identify the key research findings that would aid the research design of this study, analyzing potential weaknesses amongst literature to addressing research gaps with valuable new research insights accordingly. In order to construct this literature review chapter in a logical manner, the first part of the chapter will provide an in-depth theoretical background of bonds and bond yields, drawing upon its research importance to study with emphasis on zero-coupon bonds. The zero-coupon bond's unique characteristics are critically explored concerning its long yield spread, explaining through Piazzesi's (2010) cash flow structure of zero-coupon bonds to highlight its unique features in comparison to regular bonds. Furthermore, the academic definition and the development of yield curve concepts will be critically reviewed from its origins up to recent academic developments. The nature of yield curves and types of yield curves is explained according to empirical studies conducted to explore the relationship between the yield curve and macroeconomic dynamics. This section will provide emphasis on the key findings from major research studies conducted by scholars that indicate strong relationships between yield curves and its predictive power for future economic activities.

Moreover, the standard yield curve modelling methods conducted by central banks of different national governments in shaping and designing monetary policies are critically reviewed. It is particularly emphasizing Nymand-Anderson's (2018) extensive literature conduct to yield curve modelling by the European Central Bank. In order to gather further theoretical insights on the application of yield curve methods on the predictive behaviour of the future macroeconomic outlook. An in-depth analysis of widely applied economic theories such as Modigliani's (1944) liquidity preference theory of interest, the pure expectations hypothesis (Campbell, 1995) and the segmented market theory developed by Kidwell \& Koch (1983) is conducted with a discussion of other scholar studies. These studies have applied these theories to modelling yield curves. The next section will critically review empirical studies that have been conducted with the adoption of traditional spline-based models when constructing the yield curve and parsimonious based models with the differing functions explained from significant research studies in respective fields. An extensive review of empirical yield curve studies with the application of the NelsonSiegel (1987) model is conducted with an in-depth analysis of its dynamic latent factors and how these factors have been applied, utilized, or criticized from other research studies. Various versions and modification of the Nelson-Siegel (1987) model are critically discussed as the purposes of changing from the original NS model. It evaluates following its potential weaknesses in order for the researcher to overcome such barriers when applying this model on the zero-coupon bond yields and its predictive power of future Chinese economic output growth. The final section of this chapter will summarize the key findings of related empirical research studies conducted in the field of yield curve modelling and its predictive powers.

\subsection{Theoretical background of bonds and bond yields}

According to Harford \& Uysal (2014), a bond is defined as a debt instrument that requires the issuer, also referred to as the debtor or borrower, to repay the investor the invested value on top of designated interests over a set period of time. Alternatively, Kuehn \& Schmid (2014) defines a bond as an interest rate coupled loan whereby the bond issuer is required to pay predefined levels of interest to the investor across a range of periods, usually annually. Upon the reaching of the bond maturity, the principal amount of investment will be repaid. However, the nature of bonds is vulnerable to particular fluctuations in its price. The price of the bond represents only the present value of cash flows and is continuously fluctuating according to supply and demand movements (Duffee, 1998). The yield of a bond is defined by Yawitz (1977) as the realized values on a bond from an investment perspective, representing a function of the price of the bond and its interest/ coupon payments to the investors rather than its purchased face value. Subsequently, the relationship between a bond and bond yield can be measured in accordance with the time value of money and the compound interest payment rates, commonly calculated by various approaches such as yield to maturity, bond equivalent yield, and the effective annual yield (Yawitz, 1977). In general, a fundamental characteristic of bonds includes the price change when experiencing a change in the required yield. Ass the required yield increases, a decline in the present value of cash flow will be decreased, and thus the bond price will correspond in similar drops in value. Alternatively, when the present value of cash flow rises, the required yield will fall, and thus the bond price will be increased (Sarig \& Warga, 1989).

The duration of bonds typically ranges with the maturity range between one year and thirty years. Issuers of bonds are commonly categorized into three distinctive groups of government bonds, corporate bonds (domestic and foreign), and municipal bonds (Fabozzi \& Mann, 2012). According to Fabozzi \& Mann (2012), treasury bonds are fixed-rate debt securities issued by the government to finance its budget deficits. It is often characterized by being lower risks and holds lower yields, which implies stronger investment values, particularly in economic downturns. Treasury bonds include various debt instruments such as treasury bills, treasury notes, and treasury inflation-protected securities (TIPS) that vary by distinctive maturity length and level of coupon interests (Cieslak \& Povala, 2015). Alternatively, corporate bonds are debt instruments issued by corporations and poses greater 
investment risks than government-issued treasury bonds; thus, higher coupon payments are often incentivized to encourage investors to purchase. Corporate bonds are coupled by the debt obligation for corporations to pay bondholders periodic interests on designated dates prior to reaching the maturity when full repayment of the face value is returned (Elton et al, 2001). A wide range of corporate bonds can be purchased, including floating rate corporate bonds, zero-coupon bonds, and convertible bonds, each distinctive withholding features in the nature of purchased bond prices and coupon/ interest payments (Elton et al, 2001). Another type of bonds under the municipal category are issued as debt securities by regional, local governments. These are commonly purchased to raise capital to fund public works in the local regions, such as transportation and social welfare infrastructure developments (Wang et al, 2008). A common characteristic of municipal bonds is often associated with its taxfree incentive, increasing its investment values, particularly for wealthy individuals who are in higher tax brackets (Temel \& BMA, 2001). Given the diverse nature and distinctive characteristics of different bond types, government-issued bonds (treasury bonds) are commonly studied when exploring and forecasting the overall macroeconomic environment as shown in studies conducted by Adofu \& Abula (2010), Dotsey (1998) \& Harvey (1993). Therefore, this research will specifically focus on treasury bonds, and the following section will critically review the relationship of zero-coupon bonds in particular with forecasting future economic activities.

2.1.1 Zero-coupon bond and long yield spread

The fundamental differences between a regular bond and a zero-coupon bond lie in the nature of interest/ coupon payments to bondholders. Bondholders of regular bonds are subject to regular coupon payments at designated coupon dates (Chance, 1990). In contrast, zero-coupon bonds do not have similar periodic coupon payments. However, they are incentivized by the discounted face value of the bond purchase, at which the amount will be repaid to the bondholder when the zero-coupon bond reaches maturity (Chance, 1990). According to Singleton \& Umantsev (2002), the maturity rates of zero-coupon bonds tend to have longer rates than regular bonds, typically between ten to thirty years, as investors are able to leverage the investment values for the long term investment goals. The discounted rate of the zero-coupon bond face value implies that investors with limited budget can invest with lesser capital. That is expected to considerably grow over its maturity years, exceeding anticipated inflation rates and representing a low-risk investment method (Dai et al, 2007). Zero-coupon bonds can be purchased from a range of secondary market issuers, including government, corporate and municipal entities. The US treasury bills are a prime example of zero-coupon bonds that are issued by the US treasury department but are not issued in other countries such as Italy or Russia (Duffie et al, 2003). The unique characteristics of zero-coupon bonds present advantages and disadvantages as it would encourage or discourage the government from issuing such bonds due to their economic conditions. According to Duffie et al (2003), governments tend to issue zero-coupon bonds to protecting stock holdings, particularly in stressed economic environments, reducing rates to stimulate economic activities. Significant reduction in rates has found to correlate to drastic increases of zero-coupon bond demands, offering lesser risky long-term investment opportunities with a predictable rate of return on investment gains (Duffie et al, 2003).

Alternatively, there are numerous drawbacks of zero-coupon bonds which discourage issuers from selling such bonds. These bonds are highly subjected to interest rate risks as substantial increases in interest rates. It would result in the subsequent fall of zero-coupon bond values on the secondary market, being particularly vulnerable and sensitive to interest rate changes under the concept of duration risk, according to Chance (1990). Another key risk of zero-coupon bonds lies in the nature of taxation for these bonds, the difference in value between the discounted bond price paid at the beginning in comparison to received face amount upon maturity, also commonly referred to as the imputed interest. This value difference can be outweighed by the required tax paid as phantom imputed interest income every year, similar to tax payments on regular bonds despite the lack of annually returned interests which adds risks to cash-constrained investors (Singleton \& Umantsev, 2002). In Piazzesi's (2010) research study, the long yield of zero-coupon bonds is modelled in terms of structural cash flow as a financial contract, as shown in figure 1 below. The long yield of zero-coupon bonds is explained in Piazzesi's (2010) model with two unique features. Firstly there is an initial principal payment by the investor. Secondly, there will be an amount of redemption payment from the bond issuer to the bondholder upon contract expiry (maturity) which is formed by the totalling of interests and principal payments. Furthermore, it is widely recognized that zero-coupon bond acts as a financial contract that has no underlying cash flow, accumulated asset values, optionality or dependences involved, providing complete control and certainty for the investor as to the time needed to receive the expected amount of returns from their initial investment. 


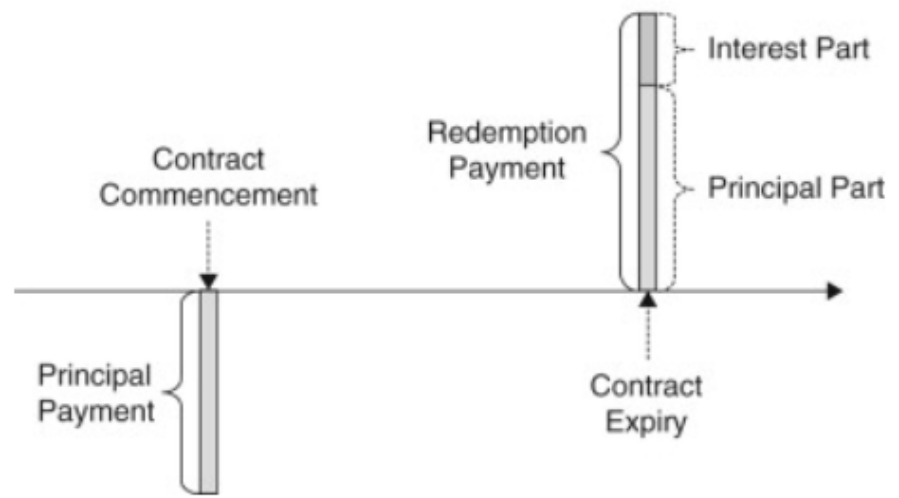

Figure 1: Cash flow structure of zero-coupon bonds (Piazzesi, 2010, p700)

\subsection{Academic definition and the development of Yield curve}

The academic definition of the yield curve is widely regarded as an econometric approach to measuring and plotting a line on the interest rates of bond yields according to maturity rates (Estrella \& Trubin, 2006). According to Zaloom (2009), the yield curve illustrates the relationship between the interest rate and the time to maturity of a particular treasury bond, plotting varying rates of interests until reaching bond maturity to offer clear indicators of potential investment gains. Moreover, the yield curve has often been studied in relation to its slope and subsequent implications on future interest rate changes and stimulation of economic activity levels, particularly for prediction imminent economic recessions as found in Wright's (2006) study. The origins of the yield curve date back on 15th August 1971, when previous U.S. President Richard Nixon announced that the U.S. dollar would no longer be primarily based on the gold standard, thereby ending the Bretton Woods gadget and initiating the generation of floating trade rates (Weir, 2006). Subsequently, the resulted floating exchange charges made investment gains increasingly difficult for bond traders, inclusive of those at Salomon Brother in New York City. In the mid-1970s, stimulated by using the head of a bond lookup at Salomon, Marty Liebowitz, traders commenced questioning about bond yields in new ways. Rather than suppose of each maturity (a ten-year bond, a five-year.) as a separate marketplace, they began drawing a curve via all their yields. The bit nearest the current time grew to become known as the short end - yields of bonds similarly out became, naturally, the lengthy end (Zaloom, 2009). Academics had to play seize up with practitioners in this matter as academic debates over yield curves grew in practice. One significant theoretic development was proposed by a Czech mathematician Oldrich Vasicek, who argued in a 1987 paper Probability of loss distribution that bond prices all along the curve driven employing the shortstop (under chance neutral equivalent martingale measure) and as a consequence by way of no permanent interest rates (Vasicek, 1987).

The mathematical model from Vasicek's (1987) work reinforces the mean-reverting values from the OrnsteinUhlenbeck process. However, Vasicek's (1987) arguments have often been criticized due to the fact the proposed model instilled higher likelihoods for instability in quick price, resulted in inflexibility to developing yield curves of distinct shapes (Stoffberg \& Vuuren, 2016). Subsequently, Vasicek's proposed model on the yield curve has been superseded by alternative models together such as Hull's (1996) Hull-White interest rate trees model which permits for time-varying parameters in the process. In addition, the CIS model developed by Cox et al (1985) further modified the process, adding an intertemporal general equilibrium model to measuring the term structure of interest rates when reflecting yield curves. Since the 1980s, substantial academic studies have been conducted to modifying and making adjustments to traditional yield curve models, the LIBOR market model, in particular, has been extensively developed to pricing interest rate derivatives in a long term approach rather than short and instant forward rates as proposed by the Health-Jarrow Morton framework (Eberlein \& Ozkan, 2005). In 1996 several derivatives traders led with the aid of Olivier Doria (the head of swaps at Germany's Bank) and Michele Faissola, attributed to an extension of the swap yield curves in all the leading European currencies. Until then, the market would give expenditures until 15 years of maturities. The group extended the maturity of European yield curves up to 50 years (for the lira, French franc, Danish krone, and many other currencies such as the ECU). This innovation was a predominant contribution closer to the issuance of lengthy dated zero-coupon bonds and the advent of lengthy dated mortgages which has contributed to the academic understanding and application of yield curves (Johnson \& Soenen, 1994).

Upon several major studies to defining and refining the purpose and characteristics of the yield curve concept, it is summarized in Ang et al's (2006) definition that the yield curve is essential a curve displaying different yields to maturity or interest quotes throughout extraordinary contract lengths ( 2 months, two years, 20 years, and others) for a comparable debt contract, describing the relationship between the level of the interest rate or the price of borrowing. Furthermore, Aljinovic et als' (2012) best-fit approach for yield curve pays emphasis on the time to 
maturity, recognizing the term of debt for a given borrower in the given currency. Moreover, yield curves are found to be commonly upward sloping whereby the longer the maturity, the higher the yield, with diminishing marginal increases (that is, as one changes to the right, the curve flattens out). According to Diebold et al (2006), substantial developments in academic studies over the application of yield curves has established a research consensus over the distinctive natures of yield curve slopes. Whereby asymptotically upward slopes indicates that the longer the maturity would typically experience higher yield rates with diminishing marginal increases overtime. This is often associated with the anticipated rise of risk-free rates whereby investors are more likely to obtain higher investment profits from investing with better future rates (Diebold et al, 2006). In the application of the arbitrage pricing theory developed by Roll \& Ross (1980), it is argued that investors who are looking to purchase long-maturity bonds desire more significant compensation in relation to inflation rates. Thus the need for higher interest rates on longer-maturity investments is apparent. Similarly, an upward yield curve slope can be explained by the capital asset pricing model (CAPM). The model explained the tradeoff between potential investment risks and expected returns, suggesting that investments with longer maturities tend to entail greater risks due to vulnerability to volatile economic conditions over the long term (Dempsey, 2013).

The contrary function (short-term interest fees higher than long-term) can also happen according to Diebold et al (2006). For example, in 2004, the yield curve for U.K. government bonds drastically changed as the yield for the 10 -year bond rose at 4.6 percent but used to be solely $4.45 \%$ for the 30 -year bond. The market's anticipation of falling pastime rates was found to key contributors to this drastic shift (Lidholdt et al, 2007). Alternatively, negative liquidity premiums can also happen if long-term traders dominate the market. Cohering to the prevailing view is that an advantageous liquidity top-class dominates, therefore the anticipation of falling activity rates will cause an inverted yield curve (Lidholdt et al, 2007). Moreover, strongly inverted yield curves have traditionally preceded economic recessions as shown in the 2000 tech bubble burst and the 2007-2008 global financial crisis that economic recessions following the aftermath of drastic economic expansions as seen in figure 2 below (Chu, 2013). In general, the nature of the yield curve is found to be directly influenced by supply and demand for investments. Whereby fluctuations in the supply end or demand end would result in the shifting of the yield curve slope. It reflects the changes in interest rates from investments in both short and long term economic volatility (Diebold et al, 2006). Nonetheless, yield curve represents a topic of academic interest due to its capability to reflecting real-life economic activities and the term structure of interest rates, often been studied to predicting future economic behaviors under the market expectation hypothesis. Therefore, it is of research importance to further explore the different types of yield curve explained in empirical academic studies to offer more in-depth foundation knowledge to fulfilling research aims as intended in the following section (Campbell, 1995).

\section{May, 1998 May, 1999 May, 2000}
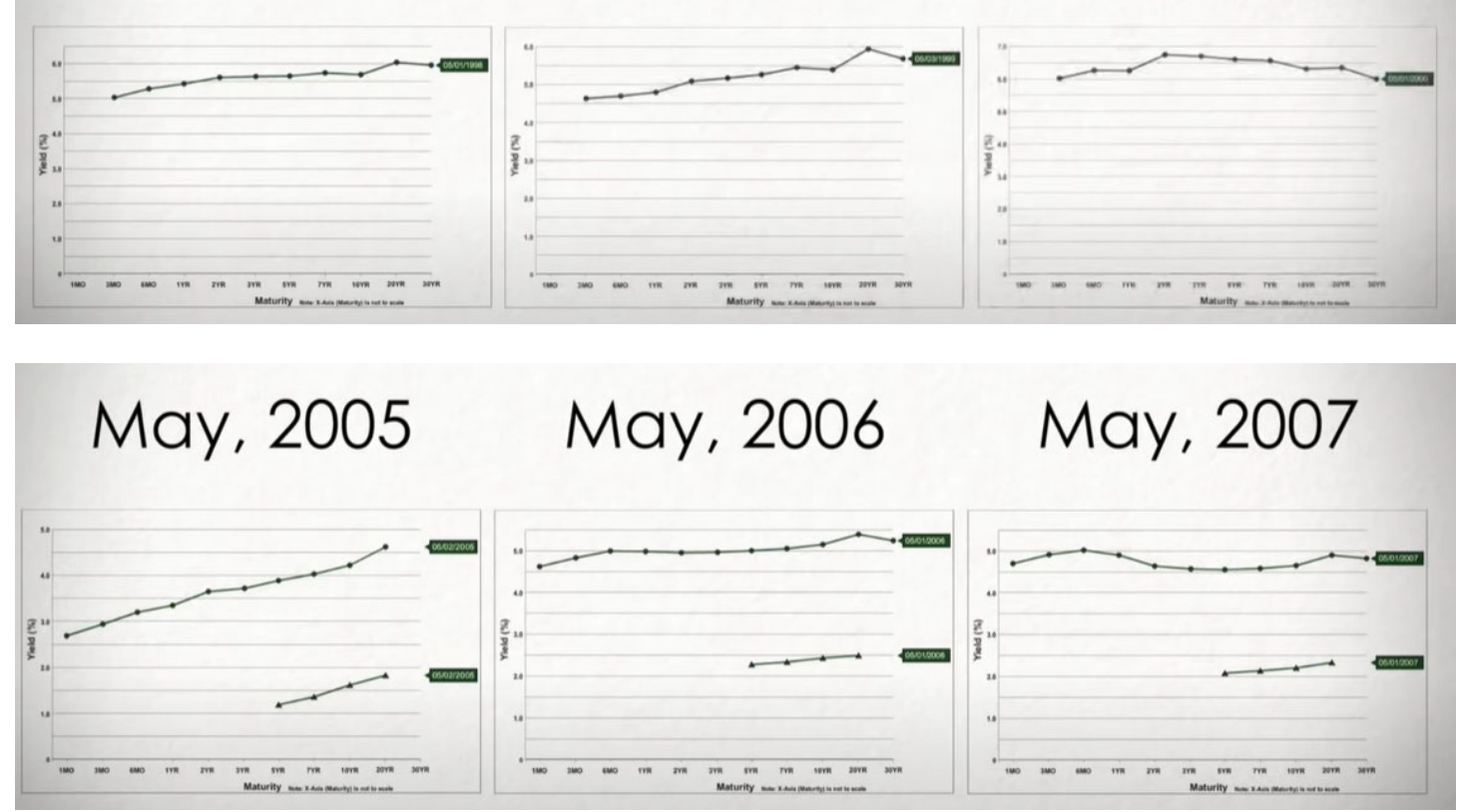

Figure 2. The yield curves leading up to the 2000 tech bubble burst and the 2007-2008 global financial crisis

(Chu, 2013)

2.2.1 Types of yield curve

It is widely recognized amongst the academic field that there exists no unified paradigm to explain the yield curve 
of investment gains for all types of treasuries, bonds and investment products due to each's unique dynamic characteristics of the investment type (Moller et al, 2006). However, Geyer et al (2004) argue that the dynamics of yield stress can be categorized under different types of yield curves, most commonly deciding the forex in which the investing securities denominate. According to Choudhry (2019), the financial function of the international locations and organizations, the usage of every currency is a principal component in deciding the yield curve. Different establishments can borrow cash at unprecedented rates, relying on their creditworthiness. Therefore, the yield curves are directly responsive to the bonds issued by governments in their very own currency are known as the authorities' bond yield curve (Choudhry, 2019). Banks with high savings rankings (Aa/A.A. or above) borrow money from each other at the LIBOR rates. These yield curves are usually a little higher than the authorities' curves. They are the most vital and widely used in the monetary markets and are acknowledged differently as the LIBOR curve and the swap curve, according to Mercurio's (2010) modern LIBOR market models. Subsequently, the government curve, the LIBOR curve and corporate curves differ. Given the nature that firms have much less creditworthiness than most governments and most giant banks, these yields are commonly higher. Corporate yield curves frequently quoted in phrases of a "credit spread" over the relevant swap curve. For the occasion, the fiveyear yield curve factor, for example, Vodafone may quote as LIBOR $+0.25 \%$, the place $0.25 \%$ (often written as 25 foundation factors or $25 \mathrm{bps}$ ) represents the spread.

According to Ang et al (2006), a common type of yield curve is defined as a normal yield curve. Since the U.S. depression era from the 1930s to the present, the yield curve has typically been regarded as "normal," which means that yields upward jab as maturity lengthens (i.e., the slope of the yield curve is positive). This upward slope reflects investor expectations for the financial system to develop in the future and, more importantly, for this growth to relate with a higher expectation that inflation will upward jostle in the future alternatively than declining (Zaloom, 2009). This nature of expectation for higher inflation changes to expectations that the central bank will tighten monetary policy via raising momentary interest prices in the future to sluggish financial boom and dampen inflationary pressure (Zaloom, 2009). Additionally, this creates the need for a threat premium related to the economic uncertainty about the future charge of inflation and the risk this poses to the future cost of money flows. Investors would thus take into account these risks into the yield curve by using disturbing higher yields for maturities that extend long into the future (Gurkaynak et al, 2007). In a positively sloped yield curve, lenders earn following the passage of time, as yields minimize and bonds draw closer to maturity (as yield deteriorate, rate increases). This is commonly recognized as a roll down and represents a significant component of profit in fixedincome investing (i.e., buying and selling, now not necessarily holding to maturity), specifically if the investment is leveraged (Gurkaynak et al, 2007). Nonetheless, it is widely believed that the normal yield curve type does not necessarily cohere to a positive slope, whereby it is common for economies to experience short term trend growth or declines. Potential deflation is rather than desired inflation in which would result in an inverted slope. In times of deflation, it is apparent that immediate cash flow presents lesser value than future cash flows, causing the yield curve to reflect a negative slope in spite of representing the normal yield curve of the measuring period as suggested by Campbell et al (2009).

Alternatively, another type of yield curve is known as a steep yield curve which is often regarded as a strong indicator to sluggish economic growth (Campbell, 1995). A steep yield curve commonly arises when the gap between short term bond yields and long term bond yields increases, suggesting that long term bond yields are increasing at greater rates than of short term bond yield. Alternatively, this can also occur when short term bond yields drastically drop despite the lack of increase in long term bond yields (Campbell, 1995). Based on historical financial trends, the differences between three-month Treasury bonds and twenty-year treasury bonds differ around two percentages. In situations when this hole increases (e.g., 20-year Treasury yield rises much higher than the three-month Treasury yield), the economic system anticipates improving shortly in the future (Bordo \& Haubrich, 2004). This type of steep yield curve is widely considered as the starting of economic growth (or after the end of a recession), whereby financial stagnation will have depressed non-permanent interest rates. However, prices start to move upwards as soon as the demand for capital is re-established by using growing financial activity (Bordo \& Haubrich, 2004). In general, a steep yield curve arises when interest rates of short term securities are lower than the interest rates paid on debt for long term securities. This type of yield curve is explained by Bordo \& Haubrich (2004) by the anticipation of rapid rises in interest rates. Thus investors are reluctant to invest in long term securities. This type of yield curve is also found to correlate to economic environments where long term credits are believed to be of higher values in the future, driving the demand for long term credit according to Mankiw \& Summer's (1984) study.

Additionally, a flat yield curve type is identified when there is minimal difference in yields between short and long term bonds with similar credit quality, commonly regarded as the transition phase between inverted yield curves and normal yield curves (Marty, 2017). According to Marty (2017), in the circumstances of similar yields amongst short and long term bonds, investors would generate lower gains from long term bonds mainly when considered in relation to associated risks with holding long term securities. This is found to be caused by falling long term interest rates in proportion to short term interest rates or the drastic increase in short term interest rates 
in proportion to long term interest rates (Marty, 2017). A flat yield curve type is usually coupled with uncertainties in the long-term macroeconomic environment, particularly after the raising of short-term target rates by the Federal Reserve as this would indicate unstable long term interest rates. According to the Barbell strategy on fixed income investment proposed by Chhacchi et al (2019), investors may be encouraged to invest half of the investment portfolio on short term bonds with the remaining half on long term bonds. This action offers greater flexibility and capability to react to sudden changes in the bond markets. Nonetheless, it is widely regarded that a flat yield curve type portrays signs of uncertainty in the economic environment. It is often found to be the transitioning phase from a positive/standard yield curve to an inverted curve type under Taylor's (1992) segmented market theory.

In situations where long term yields fall beneath short term yields, this is commonly regarded as an inverted yield curve type as investors tend to settle for a reduction in yield gains from long term bonds, assuming that an imminent economic decline draws near (Cwik, 2005). For example, the S\&P 500 stock market index experienced a drastic drop in mid-2007 from which it was recovered after seven years by 2013. Investors who had invested in 10-year treasuries in 2006 would have acquired a protected and constant yield until 2015, with the potentials to reaching higher returns than those invested in short term treasuries during the economic decline period. In Harvey's (1986) paper, the yield curve amongst US treasuries was found to be moving in abnormal trends prior the US recession, indicating that there would be a worsening economic environment in the late 70 s under an equilibrium model of the term structure of interest rates. In addition to the clear indications of signaling an imminent financial decline, inverted yield curves also mean that the market believes inflation will continue to fall (Harvey, 1986). Furthermore, in the event of no imminent recession but a short-term economic decline, a low bond yield could still get paid off in times of lower inflation rates. However, other contributing factors such as the "flight to quality" or monetary or foreign economic policy changes may result in the rising demand for bonds over the long term that would likely trigger the fall of long-term interest rates. This is studied under Greenspan's conundrum as the steady increase of short treasury yields is executed by tightened Fed policies. As well as it would restricting the rise of long treasury yields during the same period, highlighting the role and influence of the Fed on affecting long term yields as mentioned in Thorntons (2012) research study.

\subsubsection{Yield curve relationship with macroeconomic dynamics}

The relationship between the yield curve and its reflection of macroeconomic dynamics has received increasing research attention in recent decades, originating back to Vasciek's (1977) paper that studies the equilibrium characterization of the term structure in relation to three fundamental elements, including the absence of arbitrage opportunities, econometric and numerical tractability. Many econometric models have been developed to exploring the relationship of the yield curve in accordance with its term structure, assessing the set rates of fixed income securities and the associated risks coupled by fixed income investment portfolios (Dai \& Singleton, 2003). In recent academic studies conducted by Cieslak \& Povala (2016) and Davis \& Mossessian (2019), new approaches have been integrated to reflecting the yield curve against the macroeconomic dynamics experienced in the economic environment. The relationship between the yield curve and the economic environment is widely studied across time and states of nature, highlighting the vital role of bonds as an integral part of macroeconomic predictions and analysis (Cieslak \& Povala, 2016). Furthermore, a range of scholarly efforts established in exploring the relationship of the yield curve and macroeconomic dynamics have produced varying models in form and fit. These distinctive differences highlight the different approaches adopted to model the yield curve in contrast to the actual and future economic activity that can be determined by different yield curve models (Diebold et al, 2004). The large apparent gap amongst scholar efforts to developing yield curve models is explained by Diebold et al (2004) to lacking unified research focus on the roles and the expectations of inflation rates, interest rates, and predictive future macroeconomic dynamics. Nonetheless, the majority of empirical academic studies on yield curve modelling have attempted to bridge financial and macroeconomic variables, reinforcing the important role of the yield curve to the analysis of macroeconomic environments (Diebold et al, 2004).

However, research studies conducted by Dai \& Singleton (2003) neglected the macroeconomic linkages when modeling yield curves. The research imposes a zero arbitrage restriction that lacks sufficient observable factors to characterizing and explaining the entire set of yields, such as the latent factors proposed by the Niegel-Siegel model under the level, slope and curvature dimensions. Alternatively, studies conducted by Ang et al (2006) explicitly integrated these key macroeconomic determinants to performing highly accurate predictions of future economic activities under a multi-factor modelling approach on yield curves. Nonetheless, the macroeconomic linkage between the yield curve and real economic activities remain a highly respected phenomenon, reinforcing the need to integrating macroeconomic factors to performing a complete and more sophisticated yield curve model (Diebold et al, 2004). The integration of macroeconomic factors has been found to offer more generous estimation and forecasting accuracy in Cepni et als' (2018) research study, drawing upon the apparent relationship between the significance of macroeconomic information and the subsequent impacts on the yield curve. Despite the lack of integration of macroeconomic variables in various empirical studies to modelling yield curves (Dai \& Singleton, 2003; Duffie \& Kan, 1996; Knez et al, 1994), the apparent relationship between yield curves and its indicated bond market environment is widely recognized due to its facilitated predictability of inflation rates and the overall 
direction of the economy, influenced by the change in prices and interest rates from bond yields. A common approach to linking the relationship between yields curve and the macroeconomic environment is established by the connections between interest rates and bond yields. Whereby interest rates determine the number of coupon payments from bonds and the costs of bond investments is determined by their respective yields. Therefore, this research will adopt the approach to integrated macroeconomic factors in order to portray a more accurate representation of predicted future economic growth (Bauer \& Mertens, 2018).

\subsection{Yield curve methods for central banks}

Central banks often undertake the application of yield curve methods from different national governments to designing and shaping monetary policies to stimulating desired economic activities (Christensen, 2019). According to Nymand-Anderson's (2018) extensive literature review conducted toward the yield curve modelling from the European Central Bank, it is founded that the estimation of yield curves serves a key financial market indicator for monetary policymakers. The nature of changes and movement in zero-coupon bond prices following the purchased volume is found to show a correlating relationship with the generation of economic wealth and economic sentiments. It is often influenced by the domestic spending patterns governed by monetary policies established from central banks. Furthermore, the nature of price movements on all bond types is found to be clear indicators of attitudinal changes from investor expectations, particularly financial instruments issued by the private sectors where higher economic risks are perceived (Nymand-Anderson, 2018). This reinforces Braun's (2017) argument where unconventional and conventional monetary policy changes directly affect the slope of the yield curve, facilitating the planning for central banks when estimating the relationship between the investment returns against the terms to maturity rates of issued bonds at any given moment. Similarly, the performativity of the yield curve is found to enable central banks to reflect on the asset pricing process of treasury bonds, as Christophers (2017) argue that investors tend to incorporate anticipated changes in future inflation rates and real interest rates when evaluating the risks of purchasing potential bonds. It is widely accepted that investors tend to measure the price of a bond in relation to the forecasted future cash flows, deducting from inflation rates and measuring the profitability of bonds until it reaches maturity (Christophers, 2017).

From the central banks' perspective, the yield curve reflects the term structure of interest rates particularly for zero-coupon bonds where there are no associated default risks. According to Nymand-Anderson (2018), central banks would model yield curves in alignment to the nature of monetary policy shaping, leveraging valuable financial information to understanding the investor expectations on the future economic environment, hence adjusting short term rates to stimulating a positive economic outlook and fulfil targeted inflation rates. Central banks are better able to adjust their monetary policies as the relative levels of short and long term rates can influence the perception of investor expectation on the future economic outlook. It represents a useful indicator to communicate and encourage investors to purchase debt securities, as Leombroni et al (2019) argue that central banks would leverage the modelling of the yield curve as a communication strategy with investors. Subsequently, the nature of the modelled yield curve illustrates the anticipated levels of future economic activities, whereby a steepening yield curve would correlate to likely growth in economic activity in comparison to a flat or inverted yield curve where an imminent economic decline is anticipated (Leombroni et al, 2019). Furthermore, central banks would evaluate the nature of term spread between short and long rates on the modelled yield curve, whereby a prolonged period of positive spread would suggest that investors expect strong future economic outlook and thus increase in short term rates can help to accompany short term economic growth. Additionally, Nymand-Anderson's (2018) research also founded that central banks would pay strong emphasis on the longer end of the yield curve to understanding investor expectations about future inflation trends, allowing the adjustment of monetary policies to stimulating economic activities from investors.

2.3.1 Economic theories applied to yield curve methods

A major research focus of empirical studies conducted within the field of yield curve methods attempted to explore the theoretical foundation behind the term structure of interest rates and its reflection on the yield curve (Cieslak \& Povala, 2016). Modigliani's (1944) liquidity preference theory of interest has often been applied to exploring the term structure of interest rates, arguing that investors are often highly risk-averse as they are more likely to demand a premium for purchasing debt securities with a longer maturity period. This theory reinforces the fundamental economic principle where investors are assumed to favor the availability of cash at present rather than investing on debt securities over the long term, benefiting from higher flexibility and lower risks imposed from spending a significant proportion of the investment capital on future deliverables, thus requiring a risk premium to motivating the purchase of long term debt securities according to Bibow (2006). Taking into consideration the risk aversive nature of investors, the liquidity preference theory argues that investors would be encouraged to see a rising, positive slope of the yield curve as opposed to a flat or inverted yield curve. This would provide greater confidence in potential investment gains. Another economic theory that is widely applied in yield curve studies as shown in studies conducted by Campbell (1995), Taylor (1992) and Haldane (2000) suggest that nature of yield curve can be used to predict investor behaviors under the pure expectations hypothesis. According to Campbell 
(1995), the pure expectation hypothesis suggests that the nature of the yield curve is dictated by the expectation of forward rates that will take place in the future without taking into account the risk premia.

Moreover, Taylor (1992) also explored this relationship and founded that the nature of long term interest rates has been used as an accurate predictive indicator of future short term interest rates. Therefore, investors would interpret the yield curve with consideration for rolling over investments for short term bonds across a similar time period as to the remaining maturity of long term bonds when deciding whether to make a long term purchase (Taylor, 1992). The pure expectation hypothesis neglects the risk considerations on short term bonds but rather emphasis on the measurement of expected total returns from long term bonds, based on the principle that the potential returns of long term bonds should be equal or exceed the expected accumulative returns from the coupon/ interests of short term bonds (Haldane, 2000). Based on this investor perception, it is believed that the average future short term rate of bonds over its maturity period should offer equivalent returns to the longer-term rates. Particularly during a positive upward slope yield curve, the occurrence of higher long term interest rates would stimulate future increases in short term interest rates (Haldane, 2000). Empirical research data gathered from Haldane's (2000) research also founded that the application of the pure expectation hypothesis tends to result in overestimation of future short term rate increase due to the demand for risk premium. Subsequently, central banks would better understand investor expectations from analyzing the short term rates reflected on the yield curve, taking into account the risk premia in a complicated process that integrates the forecasting of changes in the risk premia over time. However, the pure expectation hypothesis is argued to offer substantial insights to interpreting investor expectations on future short term interest rates from the yield curve, particularly for bonds with shorter maturity rates where the nature of risk premia are lower and are lesser vulnerable to volatile market environments (Campbell, 1995).

The segmented market theory has also been applied to forecasting economic activities based on the nature of the yield curve, as shown in studies conducted by Kidwell \& Koch (1983), Choudhry (2008) and Van Horne (1980). Under the segmented market theory, it is argued that there are no direct relationships between short and long term interest rates as both represent independent variables that should be separately treated when explaining investor behaviors (Kidwell \& Koch, 1983). This theory argues that different types of investors purchase short and long term bonds; thus, there should be no direct correlations between the investor behaviors on short and long term bonds. Alternatively, the yield curve is believed to be influenced by the nature of supply and demand of the bonds in accordance to their distinctive types, sectors and issuer entity purpose, whereby a lack of connection is apparent. The yield curve for one type of debt securities should not be used to predicting the investor behaviors of another debt security (Choudry, 2008). Furthermore, Choudry (2008) emphasized the need to study the debt securities issued by the same issuer following its specific maturity durations. It is argued that despite debt securities are issued by the same issuer and thus have a shared vision behind the debt issues, the nature of investor purchase on bonds from a particular bond issuer is also likely differed in accordance to the maturity duration of the bond. Investors purchasing short term, intermediate-term and long term bonds are motivated by different investment preferences and characteristics, emphasizing on the investment habits of various types of investors, for example, banks are more likely to purchase shorter debt securities in comparison to insurance firms where long term securities are favored (Van Horne, 1980).

2.3.2 Spline based models to constructing yield curve

Due to the differing understanding and application of the yield curve to predicting investor behaviors and the future macroeconomic outlook, various modelling techniques have been used across the academic field to constructing the yield curve of other debt securities (Ang et al, 2006). In order to ensure maximum smoothness of the yield curve, many research studies have adopted a spline model when fitting the yield curve against forward rates as shown in studies conducted by Adams \& Deventer (1994), Loannides (2003), Bolder \& Gusba (2002) and Tanggard (1997). In mathematic terms, a spline modelling approach represents a unique interpolation function to yielding similar trends with low levels of polynomials. Bolder \& Gusba's (2002) research study applied the spline model to construct the yield curve from debt securities issued by the bank of Canada, using a piece-wise cubic modelling method with designated know points to maximizing the smoothness of the yield curve. The spline model is often applied to the yield curve in a regression spline technique, enabling the individual curve segments to freely move with higher levels of independence between the yield curve and the forward rates (Loannides, 2003). Alternatively, another study conducted by Fisher et al (1995) adopted an evolved method to smoothing the spline with the integration of excess roughness when plotting the forward rates, improving from the traditional regression spline model as it allows a stiffened yield curve to reduce potential oscillatory values that may affect the smoothness of the curve.

Central banks in the US and Japan have often adopted the spline model when constructing a yield curve against zero-coupon bonds, overcoming the limitations posed by specifying a single functional form of the yield stress across the entire maturity range of zero-coupon bonds (Yallup, 2012). The spline model allows the fitting of the yield curve on a piecewise polynomial spline function, resulting in increased accuracy with the order of the polynomial with a smoothly fitted curve. In Tanggard's (1997) study, the nonparametric smoothing of the yield 
curve is applied over traditionally cubic spline models, extending beyond traditional spline models with a wide range of knot points to generate higher levels of flexibility for spline curvature. This is widely regarded as a useful method to reducing outliers that provides minimal values to contribute to the curve of best fit, enhancing the comprehensibility of the yield curve and improve accuracy (Tanggard, 1997). Additionally, Fisher et als' (1995) study argues that there have been many research efforts to modifying the spline method in order to achieve a smooth fit of the yield curve, whereby the fundamental differences amongst these methods are characterized by the extent to and the nature of the smoothing criteria incorporated to achieve the best fix. In Green \& Silverman's (1993) research study, a variable penalty roughness smoothing criteria was incorporated to generalizing a rigid parameter that varied across different bond maturity, avoiding the volatility of curvature at the short end of the yield curve particularly for bonds with shorter-term maturity.

Alternatively, in Anderson \& Sleath's (2001) study, the US treasury bond market structure was explored with a step wide penalty function to measuring short to long term maturities in accordance to respective constant penalties, facilitating a highly complex penalty function that differed across maturities of different lengths to ensuring the smoothness of the yield curve. Another major research study conducted by Vasicek \& Fong (1982) adopted the spline model with a defined discount function to adjusting the exponential form to better fit the bond price from US treasury bonds, it was founded that the derived yield better portrayed the securities with no arbitrage pricing and those with fixed income derivative financial instruments. Furthermore, Vasicek \& Fong's (1982) study arranged coefficients to ensure that the resulted spline would directly coincide with the yield data of US treasury bonds. The adoption of spline methods to modeling yield curve has long been apparent in empirical literature. Whereby the intended use of the gathered financial data dictates the nature of the chosen smoothing criteria, allowing researchers to best fit the curve on data. That is comprised of multiple segments, overcoming traditional singular functional methods to plotting spot rates where outliers would affect the curvature of the yield curve particularly for zero-coupon bonds (Yallup, 2012).

2.3.3 Parsimonious based models to constructing yield curve

Parsimonious models are also widely applied in the construction of yield curves as Friedman (1977) first attempted to examining the entire term structure of the yield in a more compact approach using multiple parameters. According to Friedman (1977), a economical model approach to modelling yield curves. Which is essential to reflecting the flexibility of various ranges of shapes that are tied to yield curves, taking into account the potential natures of normal, flat, humped or inverted yield curve shapes to predicting the long term economic outlook. Another study conducted by Shiller \& McCulloch (1990) proposed the measurement of present value functions under a piecewise polynomial spline method and founded that the resulted yield curve projected an unusual upward climb at the end of the maturity ranges despite a lack of apparent evidence. It highlights the limitations of a spline method. Thus parsimonious modelling approach on yield curve has been widely applied particularly to predicting future economic activities outside the sample maturity range (Shiller \& McCulloch, 1990). Furthermore, economical models enable the capturing of stylized facts, facilitating a more accurate description of the forward rate curve as the long term asymptotic values. While the estimated interval levels are considered, this is also spread between long and term rates to ensure a thorough understanding on the yield differences between the spread range to enhance its predictive power on future economic activities (Nelson \& Siegel, 1987).

In Aljinovic et als' (2009) paper conducted to exploring the term structure of interest rates in the yield curve of debt securities in Croatia, an economic modelling approach was adopted to identifying the magnitude and directions of yield curve movements. The paper measures the positioning of the movements across various stages of the yield curve to predicting forward rates with monotonic and humped curve slopes. Aljinovic et als' (2009) study founded that the application of parsimonious models on yield curves would facilitate the allocation of appropriate weights across measured components across the yield curve, allowing the generating of different yield curves to portray better and predict future economic activities. According to Nelson \& Siegel (1987), the dynamics of the yield curve require a parsimonious modelling approach to capturing and analyzing the causes of different shapes experienced across the entire yield curve. This would aid the development of a more thorough understanding over the long-run level of forward rates without the neglecting of meaningful slope and hump throughout the yield curve, which would result in the occurrence of undesirable or misleading predictions. Moreover, Landau et al's (2000) research study founded that the forward rates of the yield curve are asymptote horizontal towards the longer end to maturity as the expected future interest rates in the long future is commonly assumed to be lesser distinguishable. If It is model by spline models, thus reinforcing the need to adopting a parsimonious modelling approach which would give better estimations on yield curves for longer maturities with closer fit with yield data. In general, Nelson-Siegel's (1987) dynamic yield curve model has been widely applied to construct yield curve models under the parsimonious approach, which is facilitated by the model and enhancing the predictability to future and longer-term economic activities. It can be seen in studies conducted by Diebold \& Yue (2008), Diebold \& Rudebusch (2013), Coroneo et al (2011), Krippner (2015) and Gilli et al (2010). The following section will critically explore empirical literature conducted to modelling yield curves with the NelsonSiegel model, exploring its unique parameters, characteristics and generated values from empirical research studies. 
This research study will adopt to modelling the yield curve of zero-coupon bonds in China.

\subsection{Empirical yield curve studies with application of Nelson-Siegel (1987) model}

The Nelson-Siegel (1987) model is widely regarded as a popular parsimonious model to exploring the polynomial function of the yield curve to explaining and predicting future economic directions (Ang et al, 2006). The research study conducted by Adynmomunov (2013) extended upon the dynamic version of the Nelson-Siegel (1987) yield curve model proposed by Diebold \& Li (2006) to examine the predictive power of information contained in the entire yield curve for real output growth. The choice of the dynamic Nelson-Siegel (1987) model is relative to the parsimony values offered in predictive power in comparison to other yield curve models, mainly traditional spline model due to its great out-of-sample forecasting performance for future yields. The model shows the entire term structure of interest rates incorporating three latent factors. In Diebold \& Li's (2006) study, these factors are interpreted as the level, slope, and curvature of the yield curve. Hannikaninen's (2017) study also considered the predicting power of the yield curve factors for the U.S. industrial production growth by using the Dynamic NelsonSiegel (1987) yield curve model. It leads to four conclusion points, where among the three yield curve factors, the slope is the most informative leading indicator. Secondly, the slope estimated from the entire yield curve produces more accurate forecasts than the empirical scope. Thirdly, the predictive powers of the individual components of the yield curve fluctuate over time. Fourthly, the slope tends to better forecast output growth when inflation is highly persistent (Hannikaninen, 2017). Ang et al (2006) also adopted this dynamic model for predicting GDP growth and yields that characterize GDP expectations. They found that indicating the maximum maturity difference's yield curve model can guide the right spread maturity in forecasting GDP growth. However, it is an unanswered question whether the model can improve on thesis yield curve forecasts by combining both term structure information and other macro variables as evidential in Diebold \& Li's (2006) study.

Diebold \& Li's (2006) study re-interpreted the Nelson-Siegel (1987) yield curve as a dynamic model that achieves dimensionality reduction via factor structure (level, slope, and curvature). The paper's key findings showcase that 1-month-ahead forecasting results were no better than those random walk and other leading competitors; the 1-year-ahead results are much superior. Meanwhile, Benmelech \& Bordo's (2007) research study used the yield curve's level, and slope, measured by low rate and the term spread to increase the forecast-ability of predictive regressions. It was founded that the differences are quantitatively significant in addition to noticeably lower mean square errors. Alternatively, Adynmomunov (2013) applied a dynamic version of the Nelson-Siegel (1987) yield curve model to jointly model real GDP growth and yield factors. The findings show that the dynamic yield curve model produces better out-of-sample forecasts of real GDP than those generated by the transitional term spread model. The paper also finds that there is again from using the information in the curvature factor. In general, though, the yield curve is less useful out of sample for prediction of real Gross Domestic Product than the predictive power suggested by in-sample OLS recession analysis. Joslin \& Konchitchki's (2018) research study integrated the model theory with empirical data evidence that a low-dimension term structure model can continuously price bonds and related options. When the covariance structure of risk factors and market prices is not restricted, the model can capture the price dynamics in bond and bond option markets. The finding shows that the proposing model is able to capture conditional first and second moments in the data and provide model-free regression analysis (Konchitchks, 2018).

Gauthier \& Simonato's (2012) research study adopted a linearized version of the Nelson-Siegel (1987) yield curve models for the cross-sectional predict or spot yield curves from samples of coupon bonds develop and analyzed. It helped elaborate how these models can be created a straight line in the level, slope, and curvature factors and how prior information about these parameters can be incorporated in the estimation procedure. The linearized models' performance is assessed Gauthier \& Simonato's (2012) paper with a sample of U.S. government bonds. The results showed that the linearized models related favorably to the original models in terms of parameter estimate stability. Furthermore, Chen \& Niu's (2014) study proposed an adaptive dynamic Nelson-Siegel (ADNS) model would adaptively detect parameter changes and forecast the yield curve. The ADNS model dominates both the popular reduced-form and affine term structure models; compared to random walk prediction, the ADNS steadily reduces the forecast error measurements by between $20 \%$ and $60 \%$ (Chen \& Niu, 2014). Diebold \& Yue's (2008) study further expanded on the older adaptation of the Nelson-Siegel (1987) model in the earlier works of Diebold \& Li (2005). Towards a global context, I was modeling an extremely large set of country yield curves in a framework that shows for both global and country-specific factors. They found that global yield factors exist and are economically important, generally explaining significant fractions of country yield curve dynamics, with interesting differences across countries.

Another paper conducted by Yu \& Zivot (2011) extended upon the dynamic Nelson-Siegel (1987) threefactor model to a broader empirical perspective by including evaluating the state space approach and using nine different ratings for corporate bonds. They founded that the dynamic Nelson-Siegel (1987) factor AR(1) model outperforms other competitors on the out-of-sample forecast accuracy. Especially on the investment-grade bonds for the short-term forecast horizon and on the high-yield bonds for the long-term forecast horizon (Yu \& Zivot, 
2011). Annaert et als' (2013) research study also adopted the Nelson-Siegel (1987) model and demonstrated how the model could become largely collinear depending on the approximated or fixed shape factors. A simple procedure based on the regression can significantly remedy the reported problems (Annaert et al, 2013). Moreover, Alfaro (2011) further affined the dynamic Nelson-Siegel (1987) yield curve model to introduce a discrete-time version of the model, overcoming the static restrictions proposed by the original model concept, the study founded an affine process that matches the model. Another study conducted by Xiang \& Zhu (2013) adopted a regimeswitching process to the Nelson-Siegel (1987) term structure model when predicting the interest rate forecasts, incorporating macroeconomic factors and introduced a Markov chain Monte Carlo process to better estimate with the model. They found that regime shifts are important for understanding the yield curve interaction and economic activity (Xiang \& Zhu, 2013). Thus, the researcher also assumes that the two regimes are closely related to the business cycle and monetary policy during this research study.

2.4.1 Nelson-Siegel's (1987) dynamic yield curve model

In earlier yield curve model studies, one of the essential drivers of return in fixed-income portfolios has often been associated with the yield curve. Many investment tactics are expressed in terms of adjustments in the slider (Ang et al, 2006). Any discussion of fixed-income attribution consequently requires a grasp of how modifications in the curve explain, and their impact on the overall performance. Suppose one is solely interested in gross changes in the yield curve at a specific maturity. In that case, one can study the various dataset's yields, interpolate the place necessary, and there is no want to mannequin any curve section (Diebold et al, 2006). On the other hand, one needs to describe curve actions in terms used by merchants (or extrapolate) and the shapes of evaluations. The most often used nomenclature for describing yield curve adjustments makes use of the phrases shift, "twist" or "butterfly" according to Diebold et al (2016). Under this shift, the degree to which a curve has moved upwards or downwards, in parallel, across all maturities shows the diploma to which the curve has steepened or flattened (Nelson \& Siegel, 1987). For instance, Finlay \& Chambers (2009) attempted to show the Australian yield curve's steepness as the difference from the 10-year bond future yield to the 3-year bond prospective yield. Curvature (or butterfly, or curve in the other word) measures the diploma to which the period structure has become higher or much less curved. For example, a yield curve that can be equipped to a straight line is well-known and shows no curvature. To describe these actions in numerical terms commonly requires becoming a model to the found yield curve with a restricted range of parameters (Finlay \& Chambers, 2009). These parameters can then be translated into the shift, twist, and butterfly moves - or something other interpretation the dealer chooses to use. The Nelson-Sigel (1987) model is frequently used for extrapolating CDS. Two of the most broadly used models are polynomial functions and the formula of the Nelson-Sigel polynomial factors are shown in the following equation.

$y_{t}(\mathrm{~T})=\beta_{0 t}+\beta_{1 t}\left(\frac{\left(1-\exp \left(-\lambda_{t} / \mathrm{T}\right)\right.}{\lambda_{t} / \mathrm{T}}\right)+\beta_{2 t}\left(\left(\frac{\left(1-\exp \left(-\lambda_{t} / \mathrm{T}\right)\right.}{\lambda_{t} / \mathrm{T}}\right)-\exp \left(-\frac{\lambda_{t}}{\mathrm{~T}}\right)\right)(1)$

Where $\mathrm{y}(\mathrm{m})$ and $\mathrm{m}$ areas above, and Beta $0,1,2$, and $\mathrm{T}$ are parameters to be fitted through a least-squares or similar algorithm. According to Diebold \& Li's (2006) research study, Beta 0 is interpreted as the long-run levels of interest rates (the loading is 1 , it is a constant that does not decay). Additionally, Beta 1 represents the shortterm component (it begins at 1 , and decays which mean the function between the ordered set and quickly to 0 ). Also, Beta 2 represents the medium-term component (it begins at 0 , increases and then collapse to zero). The $T$ value represents the decay factor whereby small values produce slow decay can better fit the curve at long maturities. At the same time, large amounts provide fast decay and could be better fit the curve at short maturities: $\mathrm{T}$ also governs where beta 2 achieves it's maximum (Diebold \& Li, 2006). However, in more recent studies conducted by Svensson (1994), Nelson-Siegel's (1987) dynamic yield curve was further modified to take into account a second hump term and was developed into the Nelson-Siegel-Svensson (NSS) model. The additional term on the formula is shown as follows:

$$
+\beta_{3 t}\left(\left(\frac{\left(1-\exp \left(-\lambda_{t} / T_{2}\right)\right.}{\lambda_{t} / T_{2}}\right)-\exp \left(-\frac{\lambda_{t}}{T_{2}}\right)\right)
$$

This formula interprets beta two and T above, for the other simple version of Nelson-Siegel (1987), this differs to the original exponential polynomial Model, where the number of straight coefficients is free. Under this formula a new curve has been fitted. The user can also define various measures of the shift, twist, and the butterfly, and calculate their values from the calculated parameter. For example, the amount of shift in a curve modeled through a polynomial characteristic can be modeled as the difference between the polynomial parameters at successive dates (Gili et al, 2010). In practice, the Nelson-Siegel function has the benefits that it is well behaved at widely long maturities and that its measurements can be set to model any yield curve, according to Nelson \& Siegel (1987). A factor-based model of yield curve moves is calculated through deriving the covariance matrix of yield, over at predefined maturities, and calculating the eigenvectors and eigenvalues of this method. Each eigenvector corresponds to an imperative model of the yield curve. And every eigenvector is orthogonal; therefore, the curve motion on any given day is a linear aggregate of the foundation eigenvectors. The eigenvalues of this matrix are then supplied the relative weights, or importance, of these curve shifts (Nelson \& Siegel, 1987). 
According to Schmitt's (2017) research study, the Nelson-Siegel-Svensson NSS model is widely applied for modeling the yield curve. However, many empirical studies have reported 'numerical difficulties' when measuring the model. It is founded that the hassle is twofold. Firstly, the optimization trouble is not convex and has multiple nearby optima. Hence well-known strategies that are with no trouble on hand in statistical packages are no longer suitable (Schmitt, 2017). Schmitt's (2017) research study enforces and checks an optimization heuristic, different evolution, exhibiting that it is able to solve the model reliably.

Furthermore, Schmitt's (2017) work also stresses that in certain ranges of the parameters, the model is badly conditioned. Thus, estimated parameters are unstable, providing small perturbations of the data. The paper explored to what extent these difficulties affect the functions of the model. Central banks and other market members widely use the model of Nelson \& Siegel (1987) and its extension by using Svensson's (1994) modified model as a model for the term shape of hobby prices Gimenoa and Nave, 2009. The empirical literature has furnished evidence that the model can provide predictive values for forecasting the period structure. For instance, Diebold \& Li (2006) model calibration process obtained parameter values such that the model constructs yields accord with market yields, despite its apparent complexity and difficulty. According to Schmitt (2017), many scholars have mentioned 'numerical difficulties' when working with the mannequin such as Bolder \& Stréliski (1999); Gili et al (2010); De Pooter, 2007. Therefore, in this research study, the researcher intends to show the calibration of the model in more detail. Empirical study findings are accepted, and it is assumed that such problems are twofold. Firstly, the optimization hassle is no longer convex and has more than one local optima. Hence methods that are comfortably on hand in statistical programs in precise strategies primarily based on derivatives of the objective characteristic are no longer fabulous to attain parameter values. Moreover, the researcher also intends to enforce and take a look at an optimization heuristic, differential evolution when attaining parameters, which is argued by Storn (1996) that differential evolution gives options that healthy the records very well. Secondly, this research study will also stress that in positive degrees of the parameters, the model is inadequately conditioned, whereby parameters are not stable, particularly given only tiny perturbations of the data.

According to Storn (1996), there are many versions of the objective function when applying the NelsonSiegel (1987) model, whereby the use of absolute values as a substitute of squares reflects a more accurate representation of scale. Likewise, Storn (1996) explored the use of bond costs as a substitute for rates, applying least-squares with a fixed $\lambda$ values strategy to set the goal function. Storn's (1996) study offers the numerical aspects of the calibration, the choice on which specification to use ought to alternatively observe from empirical checks which are past the scope of his study. An optimization approach is applied in Gili et als' (2010) study that is capable of estimating all parameters in one step for one of a kind variations of the objective function and under exclusive constraints. It is widely accepted amongst empirical studies that the NSS model works well to interpolate observed yields, however, when estimating the model with a popular optimization method, numerous restarts with specific starting values are imperative (Gili et al, 2010). Therefore, it is of research importance for researchers to adopt the model with close consideration of appropriate parameters, for example, to model the evolution over time like in Diebold \& Li's (2006) study. Hence, extra caution is essential to appreciating and setting up for possible optimization mistakes. There are two main reasons for these estimation difficulties. The first thing is that the objective function is now not convex and exhibits quite a few neighborhood minima. This is mainly true for the NSS model as the cost of the goal feature (sum of squares) may vary according to two parameters (here $\beta 1$ and $\lambda 2$ ) while maintaining the closing parameters fixed when applying the NSS model (Gili et al, 2010).

Other studies conducted by Diebold \& Rudebusch (2013) used a wide data pattern of historical yield curve data to construct a set of groundwork features that can be linearly combined to characterize these curve actions in the most cost-efficient way. The algorithm usually attributes an awful lot of the curve moves to the first groundwork function, then as a lot as viable to the second (Diebold \& Rudebusch, 2013). Since these features roughly correspond to our shift and twist motions, this strategy attributes nearly all of the curve transform to these two modes, leaving a minimal contribution from more excellent methods. Typical results attribute $90 \%$ of curve moves to shift changes, $8 \%$ to twist, and 2\% to curvature (or butterfly) movements (Diebold \& Rudebusch, 2013). However, the difficulty that these foundation functions can also be of unique values from those in which the chance is no longer widely appreciated. Firstly, there is no settlement as to what these basic modes are, on account that they rely on the historic dataset used in the calculation (unlike, say, a parallel curve shift - which may be described in only mathematical terms). For each debt securities over every evaluation interval, there will be a consequent generation in a one of a kind set of imperative modes and subsequently one of a kind attribution decomposition. Therefore, it might also be impossible to evaluate units of attribution outcomes over longer intervals (De Rezende \& Ferreira, 2013).

By determining to use such an approach, one is implicitly locked into a precise facts history and (in practice) data or software vendor according to De Rezende \& Ferreira, (2013). The structure of the modes might also no longer be in shape user expectations, and in exercise, it will be most unlikely that the portfolio will be managed and hedged concerning these essential modes. A manager is likely to view future curve movements in phrases of a simple shift and twist. The splendid gain of a factor-based strategy is that it ensures that as much curve motion 
as viable is attributed to shifting movement. That twist and curvature motion are given as small values as possible, as shown in De Rezende \& Ferreira's (2013) study. It approves curiously straightforward reporting because hardto-understand curve moves are continually assigned low weights in attribution analysis. However, this is at the price of a distortion of the different results.

On the other hand, a simple interpretation of the terms shifts, twist, curvature when utilized to yield curve actions might also nicely provide upward push to more first-order actions that are a great deal higher than traders would expect. There are additional issues in the actual definition of the phrases shift and twist, without fixing a twisted point at the outset, there is no particular value for these terms in either a Nelson-Siegel (1987) or polynomial formulation according to Exterkate et al (2013). However, the vicinity of this twist factor might also no longer match consumer expectations for more detail of the explanation of this point of view. According to Vogel et al (2007), changes in the period structure are one of the most vital sources of chance in a portfolio. Unlike a fairness price, which simply strikes one-dimensionally, the fee of a fixed-income safety is calculated from the sum of discounted cash flows, where the cut-price cost used depends on the activity rate at that maturity.

The magnitude and shape of curve adjustments are consequently of most crucial importance to fixed-income managers when applying the Nelson-Siegel (1987) model. At the most primary level, it can destroy down yield modifications in terms of treasury shift and deposit shift. At any maturity, it can examine the alternate in the point security with the adjustment in the corresponding government-backed assets, which will have the best possible credit score ranking and, therefore, the lowest yield (Vogel et al, 2007). All safes have returns equal to or larger than their equivalent maturity government securities, which act as a benchmark for moves in the marketplace. Many investment-grade securities are traded at an unfold to the treasury yield curve, with the size of this unfold relying on current financial prerequisites and the credit score ranking of the individual asset (Reitano, 1992). For instance, in 2005, General Motors' debt was downgraded to non-investment, or junk, popularity utilizing the rating agencies. As a result, the credit score spread (or return demanded through investors for holding this riskier investment) rose to employ over 150 basis points, and the cost of General Motors bonds consequently fell, the loss in performance this triggered was once attributed totally due to deposit effects (Davey \& Walsh, 2013). Since the yield of any fixed-income instrument is affected via modifications in the shape of the treasury yield curve, it is not unusual that merchants have a look at the future and past performance in the light of alterations to this curve. It is no longer inapplicable to use a single yield curve for the duration of a portfolio, even for instruments from a unique country. Inflation-linked securities use their designated yield curve methods, whereby it may not exhibit a strong relationship with the yield curve of the market abroad (Nymand-Anderson, 2018). However, short-term money market securities may additionally be better modelled by a separate model for the invoice curve rather than the Nelson-Siegel (1987) model and other markets may use the change curve as an alternative than the constructed treasury curve from the NS model.

\subsection{Summary of other related empirical studies on yield curve and its predictive power}

Other related research studies, particularly those conducted within a western research context, have also provided new insights on the modelling of the yield curve and its predictive power on the macroeconomic environment. Joslin \& Konchitchki's (2018) study provided a clear statistical relationship between low dimension term structure and its influence on the fluctuation of price bonds and related options, particularly at the occurrence when there are no restrictions on the covariance structure of risk factors and market prices. It is founded that the adoption of the Nelson-Siegel (1987) model would facilitate the capturing of first and second movements and enable more accurate predictive regression analysis (Konchitchks, 2018). Alternatively, Ehlin et als' (2018) paper identified an inflation disagreement concept when modelling yield curves, which is found to be in contrast to expected inflation where affects wedge between real and nominal yield. The finding of Ehlin et als' (2018) paper argues that inflation disagreement is positively related to consumer's cross-sectional consumption growth volatility and trading in fixed income securities - the significant model impact of inflation and controversy on yield curves. Another research study conducted by Filipova et al (2013) had developed a multivariate dynamic term structure model that takes the nonlinear relation between interest rates and the state of the economy into account. The model includes a longterm macroeconomic component as an additional yield curve risk factor. The finding shows in three dimensions, which are interpretable bond dynamics, accurate short end yield pricing, and yield curve implications. Moreover, Brancaccio et als' (2018) study conducted two empirical analyses presented to indicate that structural reforms of the labor market implemented in OECD countries between 1990 and 2013.

Brancaccio et als' (2018) research founded a clear statistical correlation associated with divergences in functional income distribution rather than GDP growth when modelling yield curves. Another research paper conducted by Chu et al (2018) shows that the Chinese economy is more volatile and less persistent than the U.S. economy: China has a shorter average duration of business cycles and recovers faster from external shocks, and the two countries move synchronously. Similarly, Levant \& Ma (2017) adopted the Nelson-Siegel (1987) model with the Markov switching function, proposes a model to capture better persistent regime changes in the interest rates of the U.S. term structure. The finding identifies the periods where monetary policy appears to have a more 
significant cause on the yield curve as well as the periods where inflation expectations likely to have a more substantial purpose in the yield process. Levant \& Ma's (2017) study also founded the convincing situation of a relationship from the regimes predicted by the difference switching models with economic circumstances and monetary policy. Another study conducted by Chadha \& Waters (2014) has estimated a macro-finance yield curve model for both the nominal and real forward curves for the U.K. from 1993 to 2008. The model can accommodate some key macroeconomic variables and allows us to estimate the instantaneous response of the yield curve. To gauge the impact of Quantitative Easing on forwarding rates. They found that ten-year nominal interest rates on average are lower, which can largely be explained by three main channels that include portfolio balance, liquidity premium, and signaling. Nevertheless, there is no sizeable impact on real interest rates.

Aguiar-Conraria et als' (2012) study also assess the variable between the yield curve and the macroeconomy. They model the shape of the yield curve by latent factors corresponding to its level, slope, and curvature. By using the tools of analysis called week, the set of variables and the length of the sample allow for a thorough estimation of the time-variation in the direction, intensity, synchronization, and the period of the yield curve and macroeconomic relation. Furthermore, Lange's (2013) research paper studied the estimation of a dynamic factor model of the yield curve for the country using a newly constructed data series on the term structure of constantmaturity, zero-coupon interest rates. The predicts support both strong macroeconomic ways on the future yield curve and yield-curve effects on future macroeconomic situations. The bidirectional causality is much greater than that found in the research for the United States. Additionally, Yallup (2012) examined the other factors of alternative models of the U.K. gilt yield curve. Using the primary data for the period July 1996 to February 2010, They suggest that the model used by the Central Bank of Canada, which both exceed the expected performance of other models and is specifically easy to estimate, is well suited to the gilt market. Yallup's (2012) founded that the slope of the treasury yield curve has regularly stated as a main economic indicator, with inversion of the curve being a concept of as a harbinger of a recession, he considers the application of a range of probit models on the use of the yield curve to forecast recessions.

Moreover, models that use each the stage of the federal cash rate and the period unfold supply higher insample fit, and higher out-of-sample predictive performance, than models with the term spread alone. There is some proof that controlling for a term top rate proxy as well may additionally help. Yallup (2012) critically explores the implications of the present-day form of the yield curve in the light of these results, and document consequences of some checks for structural stability and evaluation of out-of-sample predictive performance. Yallup's (2012) research is also consistent with the latest work with Ang et al (2006) on forecasting growth. It is determined that there are greater records in the form of the yield curve about the strange of a recession than that provided via the period unfold alone. Probit models predicting recessions that use both the level of the funds' price and the period spread supply better in-sample fit, and higher out-of-sample predictive performance, than models with the only variable called term spread. There is some evidence that was also controlling for the measure of anticipated excess returns on longer-maturity bonds that may also help (Yallup, 2012). The structure of the yield curve that has historically been the strongest predictor of recessions entails an inverted yield curve with a high degree of the nominal dollar's rate. Currently, the yield curve is flat, now not owing to a traditionally high level of the federal funds rate (Yallup, 2012). However, rather, to a low degree of distant-horizon, the future rates due in turn to some variables of low inflation expectations, low anticipated equilibrium real rates, and low term premiums. Whereby a decline in period premiums seems to explain tons of the fall instant-horizon ahead prices over a final couple of years, judging from multifactor term structure the evaluation of the yield curve with surveyexpectations for temporary interest costs at distant horizons (Yallup, 2012). While a model the use of the term unfolds predicts high differentiation of a recession in the next four quarters, the other models that Afonso \& Martins (2012) constructed that all manage for the stage of the fund's rate, do not. Alternatively, it offers a formal empirical guide to a view that has been widely expressed by commentators. That the existing flatness of the yield curve is a reflection of low term premiums as a substitute than in particular tight monetary policy, and this flatness, therefore, does not appear to herald a sharp slowdown (Afonso \& Martins, 2012).

Another study by Prasad et al (2007) explored the yield curve of US treasuries between 1961 to 2007, with further emphasis on how the yield curve predicted foreign capital movements and economic growth. Prasad et als' (2007) research founded a solid line continually compounded par-yield curve, the open circles are the real costs on all incredible coupon securities protected in the estimation, and the crosses are the estimated yields for these issues. Therefore, it is argued that the yield curve does a spectacular job becoming the whole cross-section of the treasury coupon launch with a function of only six parameters. However, potential limitations are apparent for certain momentary issues, which are attributed to the distinctive nature of those securities, and for countless securities in the two to three-year maturity vary that appear somewhat divorced from other yields on that day (Prasad et al, 2007). The experience at fitting Treasury yields on this date repeat at some stage in the sample. If the Treasury issued a full value of zero-coupon securities every day, then it is necessary to look at the yield curve and would have a whole set of the yields and forward rates. Unfortunately, this is widely recognized to date, the treasury has, as a substitute, issued a restrained number of securities with extraordinary maturities and coupons. 
Each of these is considered by Prasad et al (2007) as a basket of zero-coupon securities: one for each coupon date and one for the principal closing payment.

Moreover, Prasad et al (2007) argue that securities at all maturities and cannot solve for implied zero-coupon yields. Instead, they ought to infer what the yields would be throughout the maturity spectrum from the costs of existing coupon-bearing securities. It is what constitutes yield curve estimation. The desire in this dimension relies upon on the target that the yield curve intends to serve. A dealer searching for small pricing anomalies might also be very worried about how a specific safety is priced relative to these securities right away around it. Alternatively, a macroeconomist will likely be more interested in understanding the fundamental determinants of the yield curve. A macroeconomist also wish to use a more inflexible yield curve that smooths through such variation. Thus, it is of important cause to understand its vital determinants such as macroeconomic conditions, monetary policy prospects, perceived risks, and investors' chance preferences (Prasad et al, 2007). Considering this purpose, this research study will appoint a parametric yield curve specification.

Another study conducted by Helwege \& Turner (1999) founded that corporate bond spreads can both increase or minimize with maturity. It is also relying on the threat of the company: High-grade corporate issuers face upward-sloping savings yield curves, and speculative-grade credit score yield curves are downward-sloping or hump-shaped. The latest theoretical lookup also predicts equal credit score yield curves. Helwege \& Turner's (1999) paper reinforces the findings of Sarig \& Warga's (1989) study with clear relationships found between the risk structure of interest rates and yield curves. They argue that although market practitioners tend to agree with the academic understanding that the chance time structure is upward-sloping for excessive exceptional credits, practitioners usually do not view the slope of the curve facing high-yield issuers as negative. Helwege \& Turner's (1999) investigation provided practical values on the application of theoretical yield modelling methods from the practitioners' view of the world on real practices. In contrary to many bond pricing models' predictions, the savings yield curve for most speculative-grade firms appears upward-sloping. Mishkin's (1990) offered a quick survey of the relationship between the yield curve and future adjustments in hobby fees and inflation. The expectations hypothesis of the period structure indicates that when the yield curve is upward sloping, future shots-term and lengthy-time period activity prices predicted to rise. Empirical evidence finds that as envisioned by using the expectations hypothesis, yield spreads positively correlate with future modifications in no permanent interest rates, particularly at lengthy horizons (Mishkin 1990). However, yield spreads are negatively correlated with the next period's exchange in long-term activity rates, the contrary prediction of the expectations hypothesis. Empirical proof additionally suggests that the yield curve has almost no ability to forecast future inflation modifications for the short duration (Mishkin, 1990).

However, in Mishkin's (1990) study, it is also founded that during a year or greater, the yield curve consists of a high-quality deal of data about the future course of inflation. The yield curve is a point of the past time price yield on bonds with different phrases to maturity; however, with identical risk, liquidity, and tax considerations. In different words, the yield curve is a description of the period of the structure of interest rates. Typically, yield curves are upward sloping. For example, lengthy-time period hobby quotes are above short term interest fees; however, in different instances, they are flat or downward sloping. It raises a necessary research question over the yield curve and what determines their slope (Ang et al, 2006). It requires the understanding to why it is common to see sloping yield curves upward; however, on other occasions where downward slops are apparent. The simple principle of the yield curve is called the expectations speculation of the time shape of pastime rates and put most truly it states that the hobby fee on a long-term bond. Hua \& Wu's (2018) showed that a fundamental issue with predicting inflation fees using predictive regressions is that estimation errors can crush the statistics content. Similarly, this research paper will take into account this empirical finding and aims to address this problem with the adoption of a new strategy that makes use of a monetary-policy rule as a bridge between inflation rates and quick pastime quotes.. It also relies on the forward-interest-rate curve to predict future interest-rate movements. The 2-step manner estimates the predictive relation no longer through a predictive regression, however far greater accurately via the contemporaneous monetary-policy linkage.

According to Wright's (2006) study, historical evaluation methods show that the in-sample strategy outperforms random walk out of sample by $30 \%-50 \%$ over horizons from 1 to 5 years. Wright's (2006) study also proposes a new strategy that better predicts inflation charges except jogging predictive regressions. The method constitutes a 2-step procedure. The first step is to estimate a contemporaneous relationship between the realized year-over-year inflation charge and the yearly average of a short-term interest-rate series, whereby the subsequent relation is stimulated by employing monetary-policy guidelines. According to Taylor (1993), as central banks regulate goal interest fees to reply to inflation-rate variations, the two series showcase sturdy co-movements that can exert robustness when utilizing a spontaneous regression. The estimated relation serves as a bridge, reworking the mission of inflation forecasting to momentary interest-rate forecasting. The 2 nd step is to predict the future route of the temporary hobby price using the forward-interest rate curve, with a rolling moving-average bias correction that removes the average impact of the risk top class and convexity (Taylor, 1993). Predictive regressions have used significantly to decide the existence and statistical significance of many predictive relations; 
nevertheless, they have often observed to be ineffective in producing top of the line out-of-sample forecasting performance. Most importantly, difficulty with predictive regressions in out-of-sample checks is that even with a genuinely predictive relation, massive estimation blunders on the coefficients can crush the data content (Taylor, 1993). Therefore, in this research study, we take into consideration inflation-rate forecasting, proposing a modified approach for estimating a predictive relation except resorting to trendy predictive regressions.

The proposed modified approach drastically reduces the coefficient estimation error and considerably enhances the out-of-sample forecasting overall performance of a simple predictive relation. Ang et al's (2006) study also adopted a similar model according to the five recession prediction models from the U.S. economy treasury information, and the article examines the reliability of five popular recession prediction models. The first part provided forecasting opinions to each model's academic strengths and Ang et al (2006) assisted vice president and economists at the Federal Reserve Bank of Kansas City to make predictive forecasts. Benefited from conversations - weaknesses in predicting recessions. The part evaluates how nicely these fashions have given strengthen warning of previous recessions. Performance is measured, each with these days launched facts as well as the facts firstly reachable to analysts. The article concludes that these fashions have verified some potential in the past to predict recessions. When judiciously interpreted, the fashions can help resolve uncertainty about the possibility of a future recession (Ang et al, 2006). While a recession is often understood to be a significant and extended decline in economic activity, the use of a mannequin to predict recessions requires a unique definition. One popular definition of a recession is a consecutive 2-quarter decline in GDP.1 The enchantment of this definition stems from the truth that GDP is one of the broadest measures of commercial activity (Ang et al, 2006).

Moreover, Haubrich \& Dombrosky (1996) argues that it is difficult to associate a large decline in yield curves that do not relate to the direct decline in economic GDP output. Another definition of recession comes from the Business Cycle Dating Committee of the National Bureau of Economic Research (NBER), which formally dates the beginnings and ends of U.S. recessions. Haubrich \& Dombrosky (1996) examined that the steepness of the yield curve must be a great indicator of a viable future recession. First, cutting-edge financial coverage has an extensive have an impact on the yield curve spread and, for this reason, on actual exercise over the subsequent quite a few quarters. Secondly, an upward push in the quick charge would tend to flatten the yield curve as nicely as a sluggish real increase in the close to term. Although this relationship very possibly phases of the story, it is not the entire story. Thirdly, expectations of future inflation and actual interest fees contained in the yield curve seem to play an essential extra function in the prediction of future activity (Haubrich \& Dombrosky, 1996). The yield curve spread variable we look at here corresponds to a forward activity price relevant from three months of the bond treasury to ten years into the future. As explained by Mishkin (1990), this fee can be decomposed into anticipated actual pastime price and expected inflation components, each of which may additionally be beneficial in forecasting real growth. The anticipated actual fee can also be related to expectations of future monetary policy.

Another study conducted by Estrella \& Mishkin (1996) also examined in detail the predictive potential of these and other variables, which included interest charges via themselves, different stock market indexes, matter rate spreads, monetary aggregates (both theoretical and real). As well as the sequence of the index of leading financial indicators, an additional experimental index of main symptoms invented in King \& Watson's (1992) study that tested long-run neutrality of yield models and macroeconomic activities. Estrella \& Mishkn (1996) examined every aforementioned macroeconomic variable, identifying strong predictive power in each of the four variables. Nasruddin \& Amin's (2013) paper showed that a variety of monetary variables examine as predictors in probit models to predict the probability of a recession in Germany and the United States. Following the findings of previous scholar studies, the domestic term spread proved to be a vital predictive variable. Still, numerous lagged values of stock returns and the foreign term spread are also statistically extensive predictive variables for both countries. The interest rate that is different between the U.S. and Germany is also a beneficial predictor in the case of Germany (Nasruddin \& Amin's (2013). Examined dynamic probit models outperform the standard static model giving correct out-of-sample forecasts for the trendy recession period that started in both international locations in 2001. Nasruddin \& Amin's (2013) paper examines the overall performance of recession prediction fashions, which was based on the dynamic probit models and a range of financial explanatory variables. Following the proof in preceding studies, the term unfolds found as a beneficial predictive variable for the U.S. and German recessions.

However, according to the effects introduced in Nasruddin \& Amin's (2013) paper, inventory market returns have additional predictive electricity to forecast recession durations in each international location using the predictive records dispense in many lagged inventory returns. The momentary pastime price differential between the United States and Germany additionally has tremendous predictive content material in phrases of both insample and out-of-sample predictions to predict the German recession. The same is genuine, with the different German period unfold in forecasting the U.S. recessions. Besides, the U.S. period spread is additionally a statistically good-sized predictor in the case of Germany. Still, its out-of-sample predictive content appears to be terrible in the final recession period. Based on the comparisons between distinctive probit models, the results point out that statistically enormous additional predictive content material bought by way of permitting for dynamic 
constructions in the predictive model compared with the common static mannequin used in many previous studies (Nasruddin \& Amin, 2013). Significantly, the probit fashions with statistically significant autoregressive structure. In the model, the equation carried out a higher out-of-sample than the static and other dynamic models. Especially, the experimented autoregressive interplay models the place the U.S. term spread has an uneven effect on recession probability relying upon the state of the economy, supply accurate forecasts for the recession periods in the U.S. and Germany (Nasruddin \& Amin, 2013).

A research study conducted by Moller (2013) also shows that the forecastability of GDP increases the use of information from the term structure of yields. In contrast to preceding studies, the paper suggests that the curvature of the yield curve about to with a whole lot more forecasting energy than the yield curve. The yield curvature also predicts bond returns, showing a common component to time varied in anticipated bond returns and expected GDP growth. In necessary, instead of just the use of the short-end and long-end of the yield curve, the yield curvature element component to the importance of the usage of records in medium-term yields. It helps to enhance forecasting accuracy (Moller, 2013). The method used in Moller's (2013) paper to forecast GDP increase is analogous to the approach that Cochrane and Piazzesi (2005) used to forecast excess bond returns under the bond risk premia. Cochrane and Piazzesi (2005) showed that the movement of the shape in the linear combination of ahead costs is a sturdy predictor of bond returns. The linear combination of ahead quotes produces more predictive accuracy for bond returns than it does on the yield spread. The yield curvature thing and the consumption price factor relate to every difference and often share information. In particular, the two factors have comparable tent shapes throughout maturity. However, the two factors capture distinctive predictive patterns. Cochrane and Piazzesi (2005) show that the consumer price factor has some; however, no longer much predictive accuracy for GDP growth.

Given the widely recognized importance of the yield curvature factor, major research studies have been conducted to extensively explore its predictive power to real GDP growth (Hannikainen, 2017; Monch, 2012). According to Monch (2012), the yield curvature is found to have strong predictive power on bond returns, in contrast to consumption price factors that poses weak significance. The two elements collectively imply a common understanding of time-variation in predicted bond returns and anticipated GDP growth. According to Hannikainen's (2017) study that regresses future GDP growth on short- intermediate- and long-term yields. The regression gives rise to an apparent tent-shaped pattern in the coefficients across all forecasting horizons. The tentshaped sample motivates the construction of a single yield curvature factor, which strongly predicts GDP boom and compares favorably to benchmark predictors. These consequences preserve at each brief and lengthy horizon and maintain using each in-sample and out-of-sample analysis. Hannikainen's (2017) paper makes use of nonstructural predictive regressions; for example, the paper does not offer the monetary rationale for why the yield curvature factor predicts GDP growth. However, by extending the approach of Cochrane \& Piazzesi (2005), the paper shows that a tent-shaped yield curvature thing predicts each GDP growth and bond returns. It implies a fascinating frequent issue to time-variation in anticipated GDP increase and predicted bond returns.

Alternatively, Inekwe et als' (2018) paper show that the study offers a dynamic characterization of the link between economic misery danger and the actual economy. By using a wide range of dataset observations, new exante measures of economic distress are developed at the sector stage and used to take a look at increased developments in the U.S. economy. More specifically, Inekwe et al (2018) enhanced a comprehensive makeup for predicting ex-ante monetary distress risk, then have a look at the results of ex-ante monetary misery hazard on GDP growth. The results exhibit that over the length of monetary misery, the chance of contract GDP increase by using. The results additionally expose larger contractions in exports and investment. The outcomes remain unchanged when inner and external instruments use to tackle endogeneity issues (Inekwe et al, 2018). The prediction of financial ruin has maintained a pivotal role in credit score danger identification and assessment. Since the introduction from Altman (1977)'s paper that established a discriminant analytical method to predicting financial ruins (bankruptcy) of corporations, other methodological improvements such as the conditional logistic and the probit model have developed over time. The criticism of the discriminant analytical approach is its reliance on the assumption of multivariate normality, while the logistic and probit models are static. Concerning methodological improvement, Hensher \& Jones (2007) later introduced an advanced discrete choice model referred to as the blended logit model.

In contrast to the widespread logit model or probit model, the mixed logit model has been proven to be most effective for model suits and out-of-sample forecasts (Hensher \& Jones, 2007). In recent years, the use of panel logit models, for example, in Pindado's (2008) paper on hazard fashion, among others, are highly reputable in literature. These have the benefit of incorporating the dynamics of companies in the prediction of enterprise failure as the characteristics of corporations alternate over time. These fashions have generated constant and environmentfriendly pattern forecast (Pindado, 2008). Particularly, the argument from Shumway's (2001) study shows that static fashions cannot appropriately forecast bankruptcy. In the identification of failing firms, he introduces a mannequin that makes use of market-driven variables and argues that the model has higher out of sample forecasts. Furthermore, Tinoco \& Wilson's (2013) paper divulged the significance of a mixed model that harbors accounting, 
market, and macroeconomic variables in financial misery chance predictions. However, both accounting-based fashions and market-based fashions have remained equally important in predicting monetary misery and bankruptcy. The decision of variables that distinguish future solvent corporations from distressed firms is additionally a major determinant of a successful misery prediction model (Tinoco \& Wilson, 2013). Conventional predictors include accounting-based ratios computed from a firm's accounting statements. Grice Jr \& Dugan's (2003) paper re-examined the performance of authentic accounting-based models when applied to periods different than the length studied through pioneer authors and exhibit that these models are sensitive to time.

Pagan \& Robinson (2014) furnish an overview of models with financial/real interactions for assessing the impacts of financial effects on business cycles. The study provided an in-depth evaluation of the implications of collateral and deposit available on the real economic system. Pagan \& Robinson (2014) argues that the consequences provided through these studies depend on whether monetary constraints result in a trade in the impulse response or the importance of monetary factors are printed by their variance decompositions. Challenge is not the overall performance of these models, the capability fashions to generate recessions of the duration and severity as in the discover. Furthermore, research findings from Kiyotaki \& Moore's (1997) study on credit cycles provide theoretical relevance and also empirical significance. The notion that important macroeconomic fluctuations arise from a shock to housing demand through the dynamic interactions between investment and the land price made feasible via credit constraints. They find that housing demand shocks account for 22 to 36 percent fluctuations in output and 36 to 46 percent of the fluctuations in investments (Kiyotaki \& Moore, 1997).

Additionally, Jermann \& Quadrini's (2012) study explored the macroeconomic effects of financial shocks founded that adjustments in the credit score of prerequisites impact downturns in 1990-1991, 2001, and 20082009. A dummy with debt and fairness financing shows that almost half of output volatility is attributed to monetary shocks. They expose that temporary manufacturing choices via firms are influenced heavily with the aid of an economic shock. Inekwe et als' (2018) study has also shown the result of the finding out about provides in the empirical finance and economics literature, the dynamic relationship between financial distress and GDP increase, for example, imparting robust estimates through the CMP estimator.

Given that discrete and continuous established variables are involved, the model proposed by Inekwe et al (2018) approves such complicated linkage while relying on the maximum possible function. By accounting for cross-equation covariance amongst the equations, an effectivity realizes in the simultaneous equation model. In other words, a single equation method follows, while efficient estimates generate through robust general errors. Three definitions of ex-ante monetary misery explore in distinct models. The share of financially distressed companies every 12 months is employed to define distress at the zone level. It entails the use of information from the implied commentary and the distribution of the substantial degree of monetary distress (Inekwe wt al., 2018). Alternatively, Lee \& Werner's (2018) study founded that macroeconomics has, as usual, emphasized prices. This theoretical bias effects from the axiomatic-deductive methodology centering on equilibrium. Without equilibrium, quantity constraints are extra important than costs in figuring out market outcomes. In disequilibrium, activity prices must be some distance less useful as policy variables, and economics need to be more worried about portions (including aid constraints) (Lee \& Werner, 2018). To further investigate, Lee \& Werner's (2018) research study will test the received belief that decrease interest costs result in higher growth, and higher fees result in decrease growth.

Lee \& Werner (2018) examined the relationship between 3-month and 10-year benchmark charges and nominal GDP boom over one and a half of a century in four of the five greatest economies, discovering that pastime fees follow GDP increase and are persistently positively correlated with growth. If policymakers genuinely aimed at setting charges regularly with recovery, they would need to elevate them. It is concluded that traditional financial policy as operated through central banks for the previous half-century is flawed. Policymakers had a better center of attention on the extent of variables that motive growth. On the other hand, this research also shows that The policy device emphasized over the previous half-century via conventional economics and central financial institution publications are the interest rate, also recognized as the 'price of money' (Lee \& Werner, 2018). A considerable amount of literature pronounces the primacy of pastime prices and interest policy in macroeconomics. Nevertheless, many ecological economists argue that debt and the interest-based device may additionally be responsible for an unsustainable bias of economies in the direction of a damaging boom (Bauer \& Granziera, 2016; Diamond \& Rajan, 2001). Dating back to Dooley's (1983) study that criticized Marshall's perspective where economics has emphasized costs over quantities, it is argued that the former gave his identity to the 'Marshallian cross' of upward sloping giving and downward-sloping demand curves. The latter had to create his idea that markets are in equilibrium.

Additionally, equilibrium and optimality are also the analytical frameworks for many researchers in useful resource economics, for example, the study of Clark (1976) on the soundness of financial intermediaries. Concerning the empirical records, no systematic empirical find out about the query of how the degree of nominal interest rates is associated with nominal economic increase exists. It is surprising, especially because researchers have, over the years, discovered grounds for doubt concerning the canonical central financial institution model of 
decrease hobby fees, which resulted in higher growth (Clark, 1976). In a study conducted by Dornbusch et al (1994), it founded that in a model of capital flows, charge variables interest idea and interest differentials had little explanatory power, while extent variables did, in other words, the quantity of savings creation. Another study conducted by Leeper \& Gordon (1992) determined little guidance for the so-called 'liquidity effect' of activity fees on the money supply. Much research refers to a tremendous determined correlation between interest fees and inflation as the 'price puzzle' which was first identified by Sims (1992). King \& Levine's (1993) study did now not find evidence to guide the hypothesized relationship between actual pastime quotes and monetary growth in a cross-section of countries. Taylor (1999) determined that the link between real activity rates and macroeconomic aggregates, such as consumption and investment, is tenuous. Kuttner \& Mosser (2002) determined a tremendous correlation between real GDP growth and interest costs in the US between 1950 and 2000 .

Another study conducted by Dotsey et al (2003) examined the behavior of actual pastime rates, finding that they contemporaneously positively correlate with lagged cyclical output. It is argued that the department of commerce had not included pastime rates in its listing of Leading Indicators nor its list of coincident indicators. Instead, it considers pastime rates an indicator of economic increase (a truth not noted through proponents of the activity paradigm). Similar to the situation in Japan, where pastime rates have been falling for over two decades, especially since 1991, having these days fallen into a terrible territory, besides a genuinely identifiable positive impact on growth (Dotsey et al, 2003). It has posed a vast assignment to all schools of thought in macro-economics. Dreborg (1996) argues that when issues are complex, they impact many sectors and tiers of society. When there is a need for the first change when marginal changes within the current device are not sufficient when dominant traits are part of the problem under the essence of the back-casting approach. The time horizon is long ample to allow big scope for deliberate choice, and then we ought to shift the focal point from the place we seem to be heading, to the place we choose to go and how it should get there. Back-casting from the time horizon begins out from future states that satisfy some unique objectives can then use as a strategy to alternate our perceptions of what is viable or realistic and to increase the scope of solutions that consider in the modern setting. Such explorations that tackle sustainability are common, for example, in studies conducted by Dotsey et al (2003) and Dreborg (1996). $\beta \lambda$

However, scenarios that explore the hyperlink between monetary growth, welfare, and the environment, and future societies that do now not depend on the persevered increase are scarce, according to Evans \& Kenc (2001). One can also view the difficulty from the point of view that it is the focus on GDP boom that is the challenging issue, and not the growth in itself, and argues that society is indifferent to GDP growth. This standpoint has been termed a growth and is argued on the basis that GDP cannot be a measure of social welfare and that the constraint of positive GDP growth hampers human growth (Evans \& Kenc, 2001). Furthermore, Rawski (2001) argues that the Chinese economy would possibly have grown 2 percent or much less per year all through 1997 to 2001 as a substitute for the 7.1 percent as formally claimed. Other researchers such as Maddison \& Wu (2006) have shared this skepticism with the aid of comparing legitimate Chinese increase estimates to growth fees of a number inputs into production, such as energy, metal, and cement.

On the other hand, Holz (2014) and Perkins \& Rawski (2008) have claimed that financial information published by the Chinese government is generally accurate with high quality. In recent years, Chinese records have been at the supply of new controversy following WikiLeaks' guide of the premier. Li Keqiang, a provincial communist party secretary, admitting to an American diplomat that he monitored provincial financial pastime (Pinkovskiy et al, 2019). It founded that GDP growth leveraged the booming prices of electrical energy production, railroad freight, and financial institution loans and that the legit statistics had been "man-made" and "for reference only. The so-called Li Keqiang index regularly has been applied by way of many analysts and journalists as the simple arithmetic average of these three indicators (Pinkovskiy et al, 2019). All of the proposals for measuring the Chinese economic system's growth quotes depend on assumptions about the relationships between a range of macroeconomic proxies and financial activity, which are challenging to evaluate. Therefore, taking into account these considerations, for every regression that this research study runs, constructed forecasts for the path of Chinese economic activities will be done in a two-step process to enhance accuracy. Firstly, the researcher calculates indices of the macroeconomic proxies' growth quotes the use of the ideal weights implied via the regression coefficients from the provincial-level regressions mentioned above. The ultimate trouble is that the regression coefficients are proportional, however now not identical, to the variables' highest quality weights, and any intercept is unidentified. Hence, in the 2nd step, the researcher will normalize the resulting increase paths with the aid of regressing the authentic GDP increase route on these indices for the 2004-2012 period.

The researcher attempts to use the anticipated values of this second regression (in and out of sample) as our expected GDP increase series. The researcher also attempts to identifying possible trend blunders for the envisioned paths of Chinese GDP increase through parametric bootstrapping from the asymptotic distribution of the estimated coefficients from the provincial- stage regression. Also, the researcher will particularly emphasize GDP growth in 2015 Q4. When the financial press used to be awash with testimonies about a tough touchdown of the Chinese economy, it is rather higher. Furthermore, It quite close to the formally stated rate, with a $95 \%$ self- 
belief interval that precludes boom quotes below the officially pronounced level at that time (Pinkovskiy et al, 2019). This research study will also attain this discovery in the most comprehensive specs that consist of one of a kind units of macro proxies corresponding to the number of indices used by way of market participants to predict the Chinese economy. The research intuitive to accomplishing this is due to the fact the nighttime lights recommended by Pinkovskiey et al (2019). Furthermore, the massive weight for bank loans in the quality independent linear predictor of Chinese monetary growth, and not like freight and electrical energy growth, which fell during 2015, bank mortgage boom remained excessive over the route of that time. This research will incorporate the aforementioned key findings in empirical studies when conducting the yield curve modelling of China's economic activities between 2002 and 2019, striving to enhance its predictive power with appropriate methods employed in empirical studies.

\section{Research method background}

According to Hannikainen (2017), the dynamic Nelson-Siegel (1987) yield curve model is best used to predicting future economic activities when exploring the macroeconomic dynamics in relation to its latent level, slope, and curvature of the yield curve. This approach was first introduced in Diebold \& Li's (2006) study to expand further and develop the original Nelson-Siegel (1987) model to enhance its predictive power by incorporating macroeconomic dynamics. Therefore, the researcher adopted a similar approach and reinterpreted the original model's three components as level, slope, and curvature at period t. Furthermore, the researcher cohered to Diebold \& L's (2006) recognition that the modeled yield curve's changes and evolution evolve directly translates to changes in the macroeconomic environment that offers a rationale behind such movements. This would allow better anticipation of changes and for the model to better enhance forecasting accuracies. This data set used for this research study encompasses the financial information derived from the zero-coupon bond yields from the Department of China Central Depository and Clearing (2020), emphasizing zero-coupon bonds with maturity lengths ranging from 1, 3, 5, 10, 20, and 30 years averaged across each fiscal quarters between Q3 2002 to Q1 2019 for a total of 67 periods. The constructed yield curve coheres to the dynamic Nelson-Siegel (1987) yield curve model as shown below

$$
y_{t}(T)=\beta_{\text {level }(\mathrm{t})}+\beta_{\text {slope }(\mathrm{t})}\left(\frac{\left(1-\exp \left(-\lambda_{\mathrm{t}} / \mathrm{T}\right)\right.}{\lambda_{\mathrm{t}} / \mathrm{T}}\right)+\beta_{\text {curvature }(\mathrm{t})}\left(\left(\frac{\left(1-\exp \left(-\lambda_{\mathrm{t}} / \mathrm{T}\right)\right.}{\lambda_{\mathrm{t}} / \mathrm{T}}\right)-\exp \left(-\frac{\lambda_{\mathrm{t}}}{\mathrm{T}}\right)\right)+\varepsilon_{\mathrm{t}}
$$

Where $y_{t}(T)$ represents the yield of a zero-coupon bond with maturity at $T: \beta_{\text {level }(t)}, \beta_{\text {slope }(t)}$, and $\beta_{\text {curvature(t) }}$ denote the state of level, slope, and curvature of the yield curve, respectively. These three variables are time-varying factors. Coefficient $\lambda_{t}$ determines the exponential decay of the second and third components. Also, it is responsible for fitting the yield curve at different maturities. The shape of the yield curve modeled is directly determined by the three components and their associated weights in $\beta_{\mathrm{t}}$. The first component considers taking the value 1 (constant) as maturity closing to zero or $\infty$ which can, therefore, interpret as the overall level that equally influences short and long-term interest rates. The second component converges to one as maturity $\mathrm{T}$, and coverage falls to zero as maturity $\mathrm{T}$ closes to $\infty$ for a given $\mathrm{t}$. Thus, this component mostly influences short-term interest rates. The third component converges to zero as maturity $\mathrm{T}$ closes to zero, and as maturity $\mathrm{T}$ closes to infinity $(\infty)$. However, in this instance, it is concave in maturity $\mathrm{T}$ for a given $\mathrm{t}$. This component is, therefore, associated with medium-term interest rates.

The factor $\boldsymbol{\lambda}$ introduces a non-linearity in the above equation to fixing the Nelson-Siegel (1987) model, which does not have this parameter. The problem assumes a linear form, and the researcher pts OLS regression to estimate the relationship between independent and dependent variables to solve the linear problem. Furthermore, this research adopts Diebold \& Li's (2006) proposed two-step estimation, firstly considering the fixing of the decay factor to estimate the parameters. The second step consists of fitting a dynamic model to the factors $\beta_{\text {level }(t)}, \beta_{\text {slope( }(t) \text {, }}$

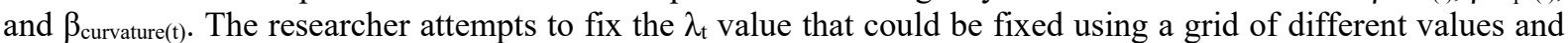
running a least squares algorithm to obtain parameter estimates, even though inequality constraints cannot handle with a standard least squares solver. Therefore, the Nelson-Siegel (1987) model's parameters can be better constructed by minimizing the difference between the model rates $\mathrm{y}_{\mathrm{t}}(\mathrm{T})$ and observed rate $\mathrm{y}^{\mathrm{M}}$ where the superscript stands for the market. An optimization problem can state as:

$$
\min _{\beta, \lambda} \sum\left(\mathrm{y}-\mathrm{y}^{M}\right)
$$

Thus, these three independent variables used to predict China's real GDP growth rate will be further tested by the regression models such as the OLS to estimate the relationship between the yield curve and China's real GDP growth rate. The data will incorporate China's real GDP growth rate from Q3 2002 to Q1 2019 quarterly. As the model is in discrete time and the data is the actual GDP growth rate, this could lead to forecasts' autoregressive nature. Therefore, It is assumed the real GDP growth rate as the logarithm of the first difference, denoted as $g_{t}$.It is also assumed the lag of yield curve function to the real GDP growth rate (denoted by n) where the value of lag 
could vary from $1,2,3,4,5,6$. The modified model is shown as below:

$$
\mathrm{g}_{t+n}=\alpha+\beta_{1} * \beta_{\text {level }(\mathrm{t})}+\beta_{2} * \beta_{\text {slope }(\mathrm{t})}+\beta_{3} * \beta_{\text {curvature }(\mathrm{t})}+\varepsilon_{t}
$$

The dependent variable refers to China's real GDP growth rate as $g_{t+n}$ where $g_{t}$ is the first difference of log of real GDP growth rate as $g_{t}=\operatorname{logGDP} t-\operatorname{logGDP}{ }_{t-1}$. Due to the real GDP growth having the problematic nature of being autoregressive, lag is denoted as $n$, the lag of level, slope, and curvature. $\beta_{\text {level }(t)}, \beta_{\text {slope(t) }}$, and $\beta_{\text {curvature(t) }}$ are the independent variables derived from the dynamic Nelson-Siegel (1987) yield curve model, particularly with the purpose of determining which factor categories of the yield curve will affect the real GDP growth rate, $\alpha, \beta_{1}, \beta_{2}$, $\beta_{3}$ are parameters and $\varepsilon_{t}$ is white noise.

\subsection{Out-of-sample forecasting of Real GDP Growth Rate}

As aforementioned in chapter two, empirical studies such as Rapach et al s' (2019) research study adopted an outof-sample forecast when predicting real GDP growth rates based on yield curves. Similarly, this research adopts a similar out-of-sample approach to compare the predictability of GDP growth under in-sample and out-of-sample forecasts. Firstly, the researcher accumulated the total sample of all T observations for $\mathrm{g}_{\mathrm{t}}$ and $\beta_{\text {level }(\mathrm{t})}$, $\beta_{\text {slope( }(\mathrm{t})}$, and $\beta_{\text {curvature(t) }}$, it is then divided into an in-sample portion composed of the first $m$ observations and an out-of-sample portion composed of the last q observations as shown below:

$$
\hat{\mathrm{g}}_{m+1}=\widehat{\alpha}_{m}+\widehat{\beta}_{1, m} * \beta_{\text {level }(\mathrm{m})}+\widehat{\beta}_{2, m} * \beta_{\text {slope }(\mathrm{m})}+\widehat{\beta}_{3, m} * \beta_{\text {curvature }(\mathrm{m})}
$$

Where $\widehat{\alpha}_{m}$ and $\widehat{\beta}_{i, m}$ are the ordinary least squares (OLS) estimates of $\alpha$ and $\beta_{i}(i=1,2,3)$ respectively. This process generates the regression $\left\{\mathrm{g}_{t}\right\}_{t=2}^{m}$ on a constant and $\left\{\beta_{\text {level }(\mathrm{t}) \text {,slope }(\mathrm{t}) \text { and curvature }(\mathrm{t})}\right\}_{t=1}^{m-1}$ The next procedure in the forecasting of out-of-sample is given by

$$
\hat{\mathrm{g}}_{m+2}=\widehat{\alpha}_{m+1}+\widehat{\beta}_{1, m+1} * \beta_{\text {level }(\mathrm{m}+1)}+\widehat{\beta}_{2, m+1} * \beta_{\text {slope }(\mathrm{m}+1)}+\widehat{\beta}_{3, m+1} * \beta_{\text {curvature }(\mathrm{m}+1)}
$$

Where $\widehat{\alpha}_{m+1}$ and $\widehat{\beta}_{i, m+1}$ are generated the regression $\left\{g_{t}\right\}_{t=2}^{m+1}$ on a constant $\left\{\beta_{\text {level }(t) \text { slope }(\mathrm{t}) \text { and curvature }(\mathrm{t})}\right\}_{t=1}^{m-1}$ proceeding with this procedure until the end of the out-of-sample period. Secondly, the researcher generates a series of q outof-sample forecasts of the real GDP growth rates based on $\beta_{\text {level }(\mathrm{t})}, \beta_{\text {slope( } \mathrm{t})}$, and $\beta_{\text {curvature( } \mathrm{t})}$, and $\left\{\hat{g}_{t+1}\right\}_{t=m}^{T-1}$ By emphasizing that this out-of-sample forecast simulates the situation of evaluating forecasting performance.

\subsection{Forecast evaluation}

The out-of-sample $\mathrm{R}^{2}$ statistic, $\mathrm{R}^{2}$ OS suggested by Rapach et al.f (2019) is used to compare the $\mathrm{g}_{t+1}$ and $\hat{\mathrm{s}}_{m+1}$ forecasts, where $\hat{\mathrm{s}}_{t+1}$ is an individual forecast based on the first out-of-sample forecast model. The $\mathrm{R}^{2}$ os is akin to the familiar in-sample $\mathrm{R}^{2}$ statistic and is given by:

$$
R_{O S}^{2}=1-\frac{\sum_{k=q_{0}+1}^{q}\left(g_{m+k}-\hat{g}_{m+k}\right)^{2}}{\sum_{k=q_{0}+1}^{q}\left(g_{m+k}-\bar{g}_{m+k}\right)^{2}}
$$

This statistic model measures the reduces the mean squared prediction error (MSPE) for the predictive regression model to the historical average forecast. Therefore, when $\mathrm{R}^{2}$ OS is more than zero, the $\hat{\mathrm{g}}_{t+1}$ forecast outperforms the historical average forecast according to the MSPE metric. Furthermore, an investigation is carried out to test whether the predictive regression model has a significantly lower MSPE than the historical average benchmark forecast. Even if there is evidence that $\mathrm{R}^{2} \mathrm{OS}$ is significantly higher than zero, its values are typically small for predictive regression models.

\subsection{Research hypothesis}

In order to fulfill the research proposed, aim and examine the predictive power of the zero-coupon yield curve constructed by the Nelson-Siegel (1987) model on China's economic growth, the following research hypothesizes are developed.

H0: China's GDP Growth rate does not correlate or have predictive power with the yield curve.

H1: China's GDP Growth rate does correlate or have predictive power with the yield curve.

\section{Results}

The chosen zero-coupon bond yield data are derived from monthly average yields on China's government zerocoupon bonds with maturities of $1,3,5,10,20,30$ years, extracted from the Department of China Central Depository and Clearing (2020). The researcher extracted all monthly average zero-coupon yields and transformed these data sets into quarterly averages to ease the data analysis and presentation, as shown in figure 3 below. 


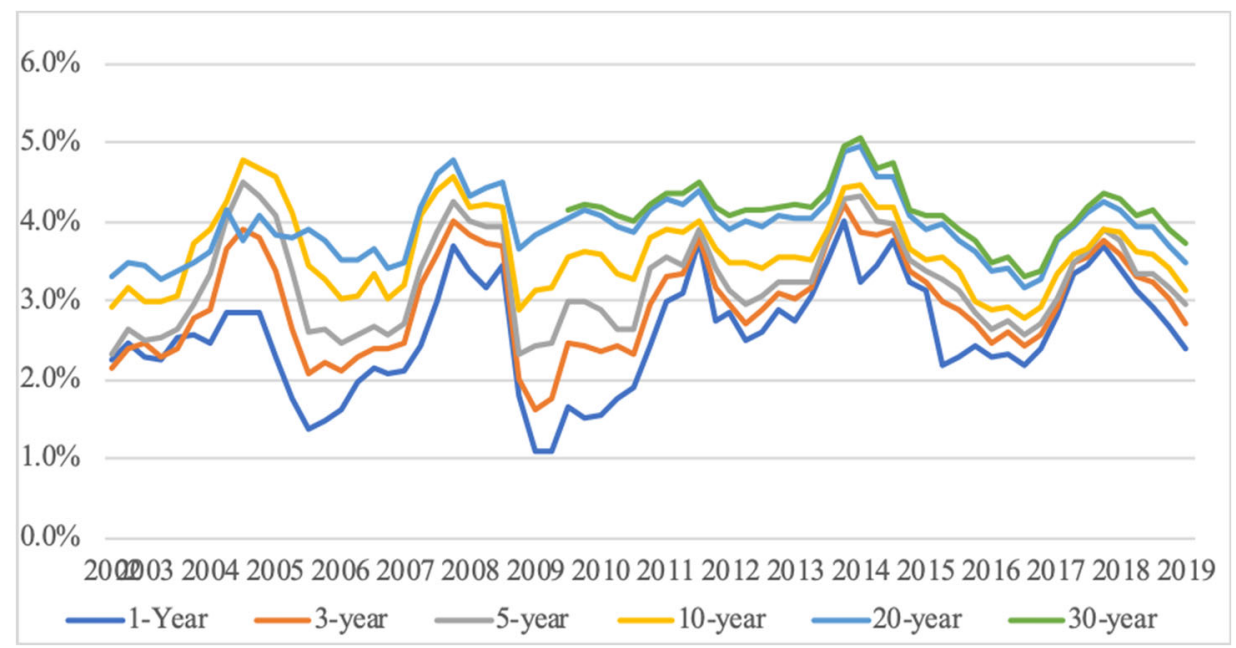

Figure 3. Zero-coupon bond yield concerning different maturities of 1,35,10, 20, 30 years between quarter 3 of 2002 to quarter 1 of 2019 (The Department of China Central Depository and Clearing, 2020)

As shown in figure 3 above, the data indicates that the bond yields across different maturities exhibit similar trends across both short, intermediary, and long term durations. Zero-coupon bond types illustrated from the data begin at Q3 2002 for maturities of 1, 3, 5, 10, and 20 years except for the 30-year bond, which the Chinese government introduced in 2009. Chinese government explored the investor preferences for longer maturity zerocoupon bonds. This yield curve data set forms the fundamental basis for addressing the yield curve for each period. Furthermore, a total of 67 yield curves are used to predicting real economic output growth (GDP) using the dynamic Nelson-Siegel (1987) yield curve model, and three independent variables are extracted for later analysis. The descriptive statistics of each zero-coupon bond yield curve according to its maturity length are summarized in table 1 below.

Table 1. Descriptive statistics of zero-coupon bond yield in different maturities

\begin{tabular}{|l|l|l|l|l|l|l|}
\hline Maturity & 1 -year & 3-year & 5-year & 10 -year & 20 -year & 30 -year \\
\hline Mean & 0.026 & 0.030 & 0.032 & 0.036 & 0.039 & 0.041 \\
\hline Std.dev & 0.007 & 0.006 & 0.006 & 0.005 & 0.004 & 0.004 \\
\hline Maximum & 0.040 & 0.042 & 0.045 & 0.048 & 0.050 & 0.051 \\
\hline Minimum & 0.011 & 0.016 & 0.023 & 0.028 & 0.032 & 0.033 \\
\hline
\end{tabular}

The table above summarizes the data's fundamental descriptive statistic on China's government zero coupon bond yield for the six different maturities.

\subsection{Multicollinearity testing}

The secondary data of dependent and independent variables (logarithm of China's Gross Domestic Product Growth Rate (GDP), The Level (Blevel) Slope (Bslope) and Curvature (BCurv)) are used to calculate the correlation coefficient that has the result, as shown in Table 2 below.

Table 2. Coefficient examination results

\begin{tabular}{|l|l|l|l|l|}
\hline & GDP & Blevel & Bslope & BCurv \\
\hline GDP & 1 & 0.064 & $-0.525^{* *}$ & 0.127 \\
\hline Blevel & 0.064 & 1 & -0.205 & $-0.854^{* *}$ \\
\hline Bslope & $-0.525^{* *}$ & -0.205 & 1 & -0.38 \\
\hline BCurv & 0.127 & $-0.854^{* *}$ & -0.38 & 1 \\
\hline
\end{tabular}

From the correlation coefficient examination results shown in table 2, it appears that the independent variables have relationships between GDP and Bslope, which is found to have a significance of -0.525 . A relationship is also found between the independent variable itself of Blevel and Bslope at the significance of 0.854. On this basis, the average of the Blevel and Bcurv and called Beta average $\left(\beta_{\text {avg }(t)}\right)$ is used instead to solve the problem of multicollinearity between independent variables. After adjusting the variable, all independent variables are better suited for further analysis of multiple regression equations. After that, the relationship between the latent factors and China's GDP growth rate is tested to achieve this. The research first checked the stationary of all factors by performing the augmented Dicky Fuller test to make sure all the factors were in a stationary state.

\subsection{Estimation of least-squares equations (OLS)}

The researcher employed the variables extracted from the dynamic Nelson-Siegel (1987) yield curve model, which transforms the zero-coupon bond yield into the independent variable under the latent factors of level, slope, and 
curvature of the yield curve. However, upon conducting multicollinearity tests, the researcher found that the latent level and curvature show a positive correlating relationship and represented a multicollinearity problem. Thus in order to over the multicollinearity problem, the researcher measured the average data between latent level and curvature under Beta average $\left(\beta_{\mathrm{avg}(\mathrm{t})}\right)$. The researcher then examined the relationship between The Beta average and Beta slope $\left(\beta_{\text {slope }(t)}\right)$ to China's Gross Domestic Product growth. The natural logarithm of China's GDP growth rate is taken into consideration to make the data more stationary. Furthermore, the researcher also tested the stationary using the Augmented-Dickey Fuller test and found a non-stationary nature in China's GDP growth rate. Thus the researcher considered taking the first-order derivative in the natural logarithm of China's GDP growth rate shown below.

$$
g_{t+n}=\alpha+\beta_{1} * \beta_{\text {avg }(t)}+\beta_{2} * \beta_{\text {slope }(t)}+\varepsilon_{t}
$$

Table 3. Multiple regression analysis of China's GDP growth rate and the states of the yield curve.

\begin{tabular}{|l|l|l|l|}
\hline$\beta_{\text {avg }}$ Factors & Coefficient & T-Stat & Sig. \\
\hline$\beta_{\text {slope }}$ & 4.1505 & 1.341 & 0.327 \\
\hline & -0.0013 & -4.533 & $0.000^{*}$ \\
\hline
\end{tabular}

$\mathrm{R}^{2}=0.296, \mathrm{~F}=13.42$, Sig. $=0.000, \mathrm{Sig}^{*}<0.05$

As shown in Table 3 above, it is founded that the value is equal to 29.6 percent. The latent factors of the yield curve, including the normal state of level and curvature and the state of the slope, can explain 29.6 percent of China's GDP growth rate. As the F value is equal to 13.42 or significance equal to 0.000 , which is less than the significant level of 0.05 , therefore $\mathrm{H}_{0}$ is rejected. The adoption of $\mathrm{H}_{1}$ shows that latent factors of the yield curve are related to China's GDP growth rate. The latent factor of the yield curve has the closest relationship with China's GDP growth rate in the state of the slope, which is related in the opposite direction with a coefficient equal to 0.0013 at a significance level of 99 percent. However, the normal state of level and curvature of the yield curve does not show any significance. The test has been run separately with the state of level and state of curvature and the returned results, which are similar, showing no sign significance for both variables. It also noted that the $\mathrm{R}^{2}$ has the same level. Though the adjusted $\mathrm{R}^{2}$ seems to be higher in the average of the state of level and curvature. The predictive regression model framework then uses to evaluate the out-of-sample forecasts.

\subsection{Out of sample forecasting of China's GDP growth rate}

This section begins with the standard predictive regression model for the yield curve, and China's GDP growth rate presents the out-of-sample results for the individual predictive regression model. An out-of-sample forecast generates using the recursive or expanding estimation, divided into different out of sample forecast evaluation periods. In order to facilitate a suitable out-of-sample size, the total observations of $\mathrm{T}$ divided is into two periods: the first period is from Quarter 3 of the year 2002 to Quarter 2 of the year 2012, which is a total sample of 40. Another period is from quarter 3 of the year 2012 to quarter 4 of the year 2019, which is a total of 27 periods. The out-of-sample regression results is shown in table 4 below.

Table 4. Out-of-sample regression results between Q3 2002 to Q2 2012

\begin{tabular}{|l|l|l|l|}
\hline$\beta_{\text {avg }}$ Factors & Coefficient & T-Stat & Sig. \\
\hline$\beta_{\text {slope }}$ & -1.1430 & -0.362 & 0.720 \\
\hline & -0.0007 & -1.446 & 0.157 \\
\hline
\end{tabular}

$\mathrm{R}^{2}=0.056, \mathrm{~F}=1.103, \mathrm{Sig}^{*}<0.05$

Based on the above out-of-sample regression findings, the results show that the R square is only 11.4 percent, which is lower than in sample regression. Moreover, there was no significance in each state of the factor of the yield curve. Similar to the out of sample forecast suggested by Campbell \& Thompson (2008) to compare the estimation and the average forecast model, the individual forecast relied on the predictive regression model equation. The $\mathrm{R}^{2}$ OS is thus used compared with the in-sample statistic, which measures the reduction in MSPE for the predictive model relative to the historical average forecast.

The results from equation (6) show that $\mathrm{R}^{2}$ os indicates to 0 . From this, it can be concluded that the out of sample forecast does not outperform the in-sample period. In other words, the in-sample information can give more explanation than the out-of-sample, as the results of the regression model can see, and the in-sample model can explain the latent factor of the yield curve of the out-of-sample, which show to have no relationship. The outof-sample results for testing the normal state of level and curvature factor of the yield curve separately are similar in that both results show no relationship between each other and the $\mathrm{R}^{2} \mathrm{OS}$ is also equal in both cases. Based on the employed methods to refining and constructing the zero-coupon yield curve from Nelson-Siegel's (1987) dynamic yield curve model, the predicted yield curve is plotted against the actual economic output/ GDP growth in China as shown in figure 4 below. 


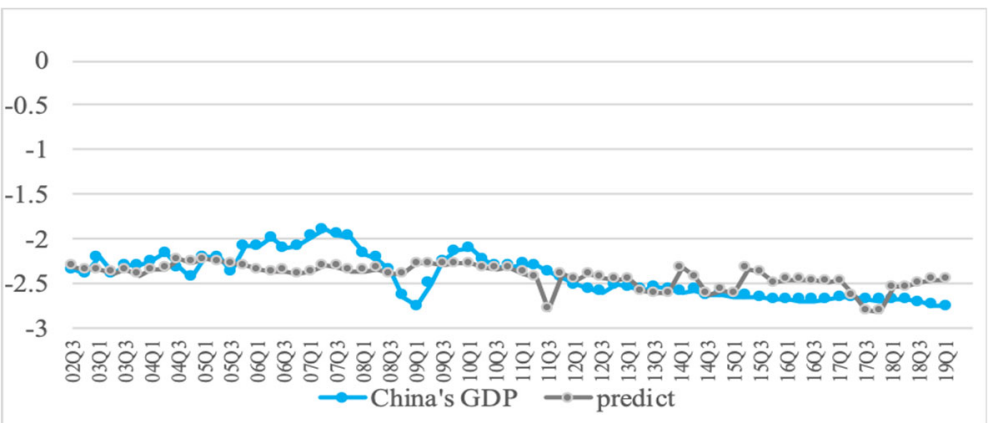

Figure 4. Prediction results against China's actual GDP growth rates.

The graph above shows the natural log of China's gross Domestic Product growth rate in the blue line, as well as China's predicted Gross Domestic Product growth.

\section{Conclusion}

Major research studies such as Diebold \& Li (2006) expanded upon Nelson-Siegel's (1987) dynamic yield curve model to enhance its predictive power with modification. Including productivity latent factors (level, slope, and curvature) and an economic variable, which is China's gross domestic product growth. The Nelson-Siegel (1987) model was adopted in this research study to improve the predictions by using an out-of-sample period where observation $\mathrm{T}$ was separated into two parts and compared with the model in and out-of-sample. To provide greater insights on the unanswered research question "does yield curve contain predictive power for China's gross domestic product growth?", research findings of this study founded a clear relationship between China's GDP growth and the yield curve constructed using data from China's government zero coupon bond data, contributing to the research field with the affirmation of the model's predictive power. This research gathered empirical financial data on the Chinese government's zero-coupon bonds with ranging maturity durations across $1,3,5,10$, 20 , and 30 years. The zero-coupon bond yield data were gathered across the period Q3 2002 to Q1 2019 for a total of 67 periods used. The extracted data was gathered in monthly periods and then averaged to obtain a figure for every three months/quarterly. Based on Nelson and Siegel's (1987) work, the dynamic Nelson-Siegel (1987) yield curve model process was adopted and modified. The model separated data into three distinctive latent factors, including the level, slope, and curvature factor of the yield curve. The level is interpreted as the long-run level of interest rates, the slope means the short-term component, and curvature is a medium-term component. Through adopting the standard least square method to minimize residual, the latent factors were obtained. These factors were used to examine if there was a relationship between China's gross domestic product growth. In research findings, the researcher founded a clear correlation problem between the independent variables where the data showed that level and curvature correlated with each other. Therefore, the averages of two independent factors were measured and used, and the tests were run based on these averages. This research conducted a multiple regression of the ordinary least square method. The final results from the regression method showed a clear relationship between the slope of the yield curve and China's gross domestic product growth.

In practical terms, the GDP of China does have a relationship with the yield curve, particularly in the shortterm duration. The results generated were also consistent with Hvozdenska's (2015) study, which also founded that the spread of yield curve demonstrated substantial predictive power to the GDP growth in Nordic countries. Moving forward further to the forecasting evaluation processes, the predictive regression model of the out-ofsample R squared statistic of the proposed R2OS suggested by Campbell \& Thompson (2008) was carried out to compare the predicted results and the average results. To further examine where an individual forecast relied on the predictive regression model or not, the data is separated into two periods with a total of 67 observations and then tested the value of R2OS. The research results founded that the out-of-sample forecasts generated the value of R2OS to equal to zero, which means the predictive regression model does not outperform the historical average according to the MSPE metric. Therefore, it can be concluded that the regression model can explain the relationship between the yield curve and China's gross domestic product growth better than the out-of-sample prediction. Further research could be extended to a broader examination of the yield curve or other factors related to China's gross domestic product growth. It is advised that future studies should apply the use of the spread of yield curve to examine whether the range could identify if there is any relationship with China's gross domestic product movements. It would be interesting to see if there are any other models or rules which could prove the hypothesis that information, data, or statistics in any period or lag would be the best for predicting China's gross domestic product growth. This can also be extended to future research studies conducted to predict the future economic activities of other developing countries that lack sufficient academic studies. 


\subsection{Research limitations}

Despite fulfilling the proposed research aim and objectives, the findings of this research study pose several key limitations as the study assumed the relationship between dependent variables and independent variables to be linear. Therefore, further studies should test the non-linear regression and compare which models are capable of describing the data best with the highest accuracy of predictive power. Furthermore, this study gathered financial data based on the zero-coupon bonds issued by the Chinese government. Therefore, this would suggest limited accuracy and applicability to fully testing the true predictive power of Nelson-Siegel's (1987) dynamic yield curve model on economic output/ GDP movements, whereby a variety of different treasuries with unique characteristics can also be studied and compared to testify its contained predictive power. Additionally, the research findings are limited by the apparent constraints and weaknesses of the Nelson-Siegel (1987) model, whereby a comparison of predictability with other yields curve models such as spline models and the NSS models would offer greater insight to comparing their predictive power, enhancing the practitioner interest to accurately predicting future economic growth in China with the most suitable yield curve modeling method.

\section{References}

Abdymomunov, A. (2013). Predicting output using the entire yield curve. Journal of Macroeconomics. 37, 333344.

Adams, K. J., \& Van Deventer, D. R. (1994). Fitting yield curves and forward rate curves with maximum smoothness. Journal of Fixed Income, 4(1), 52-62.

Adofu, I., \& Abula, M. (2010). Domestic debt and the Nigerian economy. Current Research Journal of Economic Theory, 2(1), 22-26.

Afonso, A., \& Martins, M. M. (2012). Level, slope, curvature of the sovereign yield curve, and fiscal behaviour. Journal of Banking \& Finance, 36(6), 1789-1807.

Aglietta, M., \& Bai, G. (2016). China's 13th five-year plan. In pursuit of a "moderately prosperous society" (No. 2016-12). CEPII research center.

Aguiar-Conraria, L., Martins, M. M., \& Soares, M. J. (2012). The yield curve and the macro-economy across time and frequencies. Journal of Economic Dynamics and Control, 36(12), 1950-1970.

Alfaro, R. A. (2011). Affine Nelson-Siegel Model. Economics Letters, 110(1), 1-3.

Ali, R., Sial, M. S., Brugni, T. V., Hwang, J., Khuong, N. V., \& Khanh, T. H. T. (2020). Does CSR Moderate the Relationship between Corporate Governance and Chinese Firm's Financial Performance? Evidence from the Shanghai Stock Exchange (SSE) Firms. Sustainability, 12(1), 149.

Aljinović, Z., Marasović, B., \& Škrabić, B. (2009, January). Comparative Analysis of the Stochastic and Parsimonious Interest Rates Models on Croatian Government Market. In Proceedings of Word Academy of Science, Engineering and Technology (Vol. 37, pp. 568-572).

Aljinović, Z., Poklepović, T., \& Katalinić, K. (2012). Best fit model for yield curve estimation. Croatian Operational Research Review, 3(1), 28-40.

Altman, E. I., Haldeman, R. G., \& Narayanan, P. (1977). ZETATM analysis A new model to identify bankruptcy risk of corporations. Journal of banking \& finance, 1(1), 29-54.

Anderson, N., \& Sleath, J. (2001). New estimates of the UK real and nominal yield curves. Bank of England.

Ang, A., Piazzesi, M., \& Wei, M. (2006). What does the yield curve tell us about GDP growth?. Journal of econometrics, 131(1-2), 359-403.

Annaert, J., Claes, A. G., De Ceuster, M. J., \& Zhang, H. (2013). Estimating the spot rate curve using the NelsonSiegel model: A ridge regression approach. International Review of Economics \& Finance, 27, 482-496.

Azamat, A., 2013. Predicting output using the entire yield curve. Journal of Macroeconomics 37 (2013) 333-344.

Bai, C. E., Lu, J., \& Tao, Z. (2006). The multitask theory of state enterprise reform: Empirical evidence from China. American Economic Review, 96(2), 353-357.

Bauer, G. H., \& Granziera, E. (2016). Monetary policy, private debt and financial stability risks. Private Debt and Financial Stability Risks (November 11, 2016).

Benmelech, E., \& Bordo, M. (2007). The financial crisis of 1873 and 19th century American corporate governance. Working paper, Harvard University.

Bibow, J. (2006). 20 Liquidity preference theory. a Handbook of alternative monetary Economics, 328.

Bloomberg (2017), Business of the week, available at: https://issuu.com/umsinternational/docs/bbw160817_digital, last accessed 10/11/2020

Bluwstein, K., Buckmann, M., Joseph, A., Kang, M., Kapadia, S., \& Simsek, Ö. (2020). Credit growth, the yield curve and financial crisis prediction: evidence from a machine learning approach.

Bolder, D. J., \& Gusba, S. (2002). Exponentials, polynomials, and fourier series: More yield curve modelling at the bank of canada. Available at SSRN 1082835.

Bolder, D. J., \& Stréliski, D. (1999). Yield curve modelling at the bank of canada. Available at SSRN 1082845.

Bordo, M. D., \& Haubrich, J. G. (2004). The yield curve, recessions and the credibility of the monetary regime: 
Long run evidence 1875-1997 (No. w10431). National Bureau of Economic Research.

Brancaccio, E., Garbellini, N., \& Giammetti, R. (2018). Structural labour market reforms, GDP growth and the functional distribution of income. Structural Change and Economic Dynamics, 44, 34-45.

Braun, B. (2017). Central bank planning: Unconventional monetary policy and the price of bending the yield curve.

Cai, K. G. (2003). The ASEAN-China free trade agreement and East Asian regional grouping. Contemporary Southeast Asia: A Journal of International and Strategic Affairs, 25(3), 387-404.

Campbell, J. Y. (1995). Some lessons from the yield curve. Journal of economic perspectives, 9(3), 129-152.

Campbell, J. Y., \& Thompson, S. B. (2008). Predicting excess stock returns out of sample: Can anything beat the historical average?. The Review of Financial Studies, 21(4), 1509-1531.

Campbell, J. Y., Sunderam, A., \& Viceira, L. M. (2009). Inflation bets or deflation hedges? The changing risks of nominal bonds (No. w14701). National Bureau of Economic Research.

Cepni, O., Guney, I. E., Kucuksarac, D., \& Yilmaz, M. H. (2018). The Interaction between Yield Curve and Macroeconomic Factors (No. 1802). Research and Monetary Policy Department, Central Bank of the Republic of Turkey.Cieslak, A., \& Povala, P. (2016). Information in the term structure of yield curve volatility. The Journal of Finance, 71(3), 1393-1436.

Chadha, J. S., \& Waters, A. (2014). Applying a macro-finance yield curve to UK quantitative easing. Journal of Banking \& Finance, 39, 68-86.

Chance, D. M. (1990). Default risk and the duration of zero coupon bonds. The journal of finance, 45(1), 265-274.

Chen, W., Chen, X., Hsieh, C. T., \& Song, Z. (2019). A forensic examination of China's national accounts (No. w25754). National Bureau of Economic Research.

Chen, Y., \& Niu, L. (2014). Adaptive dynamic Nelson-Siegel term structure model with applications. Journal of Econometrics, 180(1), 98-115.

Chhachhi, I. S., Trainor, W. J., \& Brown, C. L. (2019). A Barbell Strategy for Downside Protection.

Chinn, M. D., \& Kucko, K. J. (2010). The predictive power of the yield curve across countries and time (No. w16398). National Bureau of Economic Research.

Choudhry, M. (2019). Analysing and interpreting the yield curve. John Wiley \& Sons.

Christensen, J. H. (2019). Yield Curve Responses to Introducing Negative Policy Rates. FRBSF Economic Letter, 27.

Christophers, B. (2017). The performativity of the yield curve. Journal of Cultural Economy, 10(1), 63-80.

Chu, S. Y. (2013). Internet, economic growth and recession.

Chu, Z., Yang, B., Ha, C. Y., \& Ahn, K. (2018). Modeling GDP fluctuations with agent-based model. Physica A: Statistical Mechanics and its Applications, 503, 572-581.

Cieslak, A., \& Povala, P. (2016). Information in the term structure of yield curve volatility. The Journal of Finance, 71(3), 1393-1436.

Clark, R. C. (1976). The soundness of financial intermediaries. The Yale Law Journal, 86(1), 1-102.

Cochrane, J. H., \& Piazzesi, M. (2005). Bond risk premia. American Economic Review, 95(1), 138-160.

Cochrane, J. H., \& Piazzesi, M. (2009). Decomposing the yield curve. In AFA 2010 Atlanta Meetings Paper.

Coroneo, L., Nyholm, K., \& Vidova-Koleva, R. (2011). How arbitrage-free is the Nelson-Siegel model?. Journal of Empirical Finance, 18(3), 393-407.

Cox Jr, J. C. (1985). Jonathan E. Ingersoll, and Stephen A. Ross, “A Theory of the Term Structure of Interest Rates,". Econometrica, 53(2), 385-407.

Cwik, P. F. (2005). The inverted yield curve and the economic downturn. New Perspectives on Political Economy, $1(1), 1-37$.

Dai, Q., \& Singleton, K. (2003). Term structure dynamics in theory and reality. The Review of financial studies, $16(3), 631-678$.

Dai, Q., Singleton, K. J., \& Yang, W. (2007). Regime shifts in a dynamic term structure model of US treasury bond yields. The Review of Financial Studies, 20(5), 1669-1706.

Dale, G. (2012). The growth paradigm: a critique. International Socialism, 134, 55-88.

Davey, M., \& Walsh, M. W. (2013). Billions in debt, Detroit tumbles into insolvency. The New York Times, 18, 2013.

Davis, T., \& Mossessian, D. (2019). Models of the Yield Curve and Term Structure. Debt Markets and Investments, 229.

De Pooter, M. (2007). Examining the Nelson-Siegel class of term structure models: In-sample fit versus out-ofsample forecasting performance. Available at SSRN 992748.

De Rezende, R. B., \& Ferreira, M. S. (2013). Modeling and Forecasting the Yield Curve by an Extended NelsonSiegel Class of Models: A Quantile Autoregression Approach. Journal of Forecasting, 32(2), 111-123.

Dempsey, M. (2013). The capital asset pricing model (CAPM): the history of a failed revolutionary idea in finance? Abacus, 49, 7-23.

Diamond, D. W., \& Rajan, R. G. (2001, June). Banks, short-term debt and financial crises: theory, policy 
implications and applications. In Carnegie-Rochester conference series on public policy (Vol. 54, No. 1, pp. 37-71). North-Holland.

Diebold, F. X., \& Rudebusch, G. D. (2013). Yield curve modeling and forecasting: the dynamic Nelson-Siegel approach. Princeton University Press.

Diebold, F. X., Li, C., \& Yue, V. Z. (2008). Global yield curve dynamics and interactions: a dynamic NelsonSiegel approach. Journal of Econometrics, 146(2), 351-363.

Diebold, F. X., Rudebusch, G. D., \& Aruoba, S. B. (2006). The macroeconomy and the yield curve: a dynamic latent factor approach. Journal of econometrics, 131(1-2), 309-338.

Dooley, P. C. (1983). Consumer's surplus: Marshall and his critics. Canadian Journal of Economics, 26-38.

Dornbusch, R., Werner, A., Calvo, G., \& Fischer, S. (1994). Mexico: stabilization, reform, and no growth. Brookings papers on economic activity, 1994(1), 253-315.

Dotsey, M. (1998). The predictive content of the interest rate term spread for future economic growth. FRB Richmond Economic Quarterly, 84(3), 31-51.

Dotsey, M., Lantz, C., \& Scholl, B. (2003). The behavior of the real rate of interest. Journal of Money, Credit and Banking, 91-110.

Dreborg, K. H. (1996). Essence of backcasting. Futures, 28(9), 813-828.

Duffie, D., \& Kan, R. (1996). A yield-factor model of interest rates. Mathematical finance, 6(4), 379-406.

Duffie, D., Pedersen, L. H., \& Singleton, K. J. (2003). Modeling sovereign yield spreads: A case study of Russian debt. The journal of finance, 58(1), 119-159.

Eberlein, E., \& Özkan, F. (2005). The lévy libor model. Finance and Stochastics, 9(3), 327-348.

Ehling, P., Gallmeyer, M., Heyerdahl-Larsen, C., \& Illeditsch, P. (2018). Disagreement about inflation and the yield curve. Journal of Financial Economics, 127(3), 459-484.

Elton, E. J., Gruber, M. J., Agrawal, D., \& Mann, C. (2001). Explaining the rate spread on corporate bonds. the journal of finance, 56(1), 247-277.

Estrella, A., \& Mishkin, F. S. (1996). The yield curve as a predictor of US recessions. Current issues in economics and finance, 2(7).

Estrella, A., \& Trubin, M. (2006). The yield curve as a leading indicator: Some practical issues. Current issues in Economics and Finance, 12(5).

Evans, L., \& Kenc, T. (2001). Growth and welfare effects of monetary volatility. The Manchester School, 69(5), 509-533.

Exterkate, P., Dijk, D. V., Heij, C., \& Groenen, P. J. (2013). Forecasting the yield curve in a data-rich environment using the factor-augmented Nelson-Siegel model. Journal of Forecasting, 32(3), 193-214.

Fabozzi, F. J., \& Mann, S. V. (2012). The handbook of fixed income securities. McGraw-Hill Education.

Fernandes, M., \& Vieira, F. (2019). A dynamic Nelson-Siegel model with forward-looking macroeconomic factors for the yield curve in the US. Journal of Economic Dynamics and Control, 106, 103720.

Filipova, K., Audrino, F., \& De Giorgi, E. G. (2013). Monetary Policy Regimes: Implications for the Yield Curve and Bond Pricing. Available at SSRN 2232742.

Finlay, R., \& Chambers, M. (2009). A term structure decomposition of the Australian yield curve. Economic Record, 85(271), 383-400.

Firth, M., Rui, O. M., \& Wu, W. (2011). Cooking the books: Recipes and costs of falsified financial statements in China. Journal of Corporate Finance, 17(2), 371-390.

Fisher, M., Nychka, D. W., \& Zervos, D. (1995). Fitting the term structure of interest rates with smoothing splines.

Friedman, M. (1977). Time perspective in demand for money. The Scandinavian Journal of Economics, 79(4), 397-416.

Gauthier, G., \& Simonato, J. G. (2012). Linearized Nelson-Siegel and Svensson models for the estimation of spot interest rates. European Journal of Operational Research, 219(2), 442-451.

Geyer, A., Kossmeier, S., \& Pichler, S. (2004). Measuring systematic risk in EMU government yield spreads. Review of Finance, 8(2), 171-197.

Gilli, M., Große, S., \& Schumann, E. (2010). Calibrating the nelson-siegel-svensson model. Available at SSRN 1676747.

Goodhart, C. A. (2008). The background to the 2007 financial crisis. International Economics and Economic Policy, 4(4), 331-346.

Green, P. J., \& Silverman, B. W. (1993). Nonparametric regression and generalized linear models: a roughness penalty approach. Crc Press.

Grice Jr, J. S., \& Dugan, M. T. (2003). Re-estimations of the Zmijewski and Ohlson bankruptcy prediction models. Advances in Accounting, 20, 77-93.

Gürkaynak, R. S., Sack, B., \& Wright, J. H. (2007). The US Treasury yield curve: 1961 to the present. Journal of monetary Economics, 54(8), 2291-2304.

Haldane, A., \& Read, V. (2000). Monetary policy surprises and the yield curve. 
Hännikäinen, J. (2017). When does the yield curve contain predictive power? Evidence from a data-rich environment. International Journal of Forecasting, 33(4), 1044-1064.

Hännikäinen, J. (2017). When does the yield curve contain predictive power? Evidence from a data-rich environment. International Journal of Forecasting, 33(4), 1044-1064.

Harford, J., \& Uysal, V. B. (2014). Bond market access and investment. Journal of Financial Economics, 112(2), 147-163.

Harvey, C. R. (1986). Recovering expectations of consumption growth from an equilibrium model of the term structure of interest rates (Doctoral dissertation, University of Chicago, Graduate School of Business).

Harvey, C. R. (1989). Forecasts of economic growth from the bond and stock markets. Financial Analysts Journal, 45(5), 38-45.

Harvey, C. R. (1993). Term structure forecasts economic growth. Financial Analysts Journal, 49(3), 6-8.

Haubrich, J. G., \& Dombrosky, A. M. (1996). Predicting real growth using the yield curve. Economic Review, 32(1), 26-35.

Helwege, J., \& Turner, C. M. (1999). The slope of the credit yield curve for speculative-grade issuers. The Journal of Finance, 54(5), 1869-1884.

Hensher, D. A., \& Jones, S. (2007). Forecasting corporate bankruptcy: Optimizing the performance of the mixed logit model. Abacus, 43(3), 241-264.

Holz, C. A. (2014). The quality of China's GDP statistics. China Economic Review, 30, 309-338.

Hong, L., \& Xianyu, C. (2011). An Evaluation of the Accuracy of China's GDP Data Based on Total Factor Productivity. Statistical Research, 2, 81-86.

Hua, J., \& Wu, L. (2018). Monetary-policy rule as a bridge: Predicting inflation without predictive regressions. Journal of Financial and Quantitative Analysis, 53(6), 2559-2586.

Hull, J. (1996). Using Hull-White interest rate trees. Journal of Derivatives, 3(3), 26-36.

Hvozdenska, J. (2015). The yield curve as a predictor of gross domestic product growth in Nordic countries. Procedia Economics and Finance, 26, 438-445

Inekwe, J. N., Jin, Y., \& Valenzuela, M. R. (2018). The effects of financial distress: Evidence from US GDP growth. Economic Modelling, 72, 8-21.

Ioannides, M. (2003). A comparison of yield curve estimation techniques using UK data. Journal of Banking \& Finance, 27(1), 1-26.

Jalil, A., \& Feridun, M. (2011). The impact of growth, energy and financial development on the environment in China: a cointegration analysis. Energy Economics, 33(2), 284-291.

Jermann, U., \& Quadrini, V. (2012). Macroeconomic effects of financial shocks. American Economic Review, 102(1), 238-71.

Jiang, Y., Guo, Y., \& Zhang, Y. (2017). Forecasting China's GDP growth using dynamic factors and mixedfrequency data. Economic Modelling, 66, 132-138.

Johnson, R. R., \& Soenen, L. A. (1994). The European Perspective on the Composition and Variability of the ECU. Journal of Business Finance \& Accounting, 21(7), 963-974.

Joslin, S., \& Konchitchki, Y. (2018). Interest rate volatility, the yield curve, and the macroeconomy. Journal of Financial Economics, 128(2), 344-362.

Kidwell, D. S., \& Koch, T. W. (1983). Market segmentation and the term structure of municipal yields. Journal of Money, Credit and Banking, 15(1), 40-55.

King, R. G., \& Levine, R. (1993). Finance and growth: Schumpeter might be right. The quarterly journal of economics, 108(3), 717-737.

King, R., \& Watson, M. W. (1992). Testing long run neutrality (No. w4156). National Bureau of Economic Research.

Kiyotaki, N., \& Moore, J. (1997). Credit cycles. Journal of political economy, 105(2), 211-248.

Knez, P. J., Litterman, R., \& Scheinkman, J. (1994). Explorations into factors explaining money market returns. The Journal of Finance, 49(5), 1861-1882.

Krippner, L. (2015). A theoretical foundation for the Nelson-Siegel class of yield curve models. Journal of Applied Econometrics, 30(1), 97-118.

Kuehn, L. ADuffee, G. R. (1998). The relation between treasury yields and corporate bond yield spreads. The Journal of Finance, 53(6), 2225-2241.., \& Schmid, L. (2014). Investment-based corporate bond pricing. The Journal of Finance, 69(6), 2741-2776.

Kuttner, K. N., \& Mosser, P. C. (2002). The monetary transmission mechanism: some answers and further questions. Economic Policy Review, 8(1).

Landau, S., Mitchell, R. A. C., Barnett, V., Colls, J. J., Craigon, J., \& Payne, R. W. (2000). A parsimonious, multiple-regression model of wheat yield response to environment. Agricultural and forest meteorology, 101(2-3), 151-166.

Lange, R. H. (2013). The Canadian macroeconomy and the yield curve: A dynamic latent factor approach. 
International Review of Economics \& Finance, 27, 261-274.

Lardy, N. R. (1995). The role of foreign trade and investment in China's economic transformation. The China Quarterly, 144, 1065-1082.

Lardy, N. R. (2019). The state strikes back: The end of economic reform in China? Peterson Institute for International Economics.

Lee, K. S., \& Werner, R. A. (2018). Reconsidering monetary policy: An empirical examination of the relationship between interest rates and nominal GDP growth in the US, UK, Germany and Japan. Ecological Economics, $146,26-34$

Leeper, E. M., \& Gordon, D. B. (1992). In search of the liquidity effect. Journal of Monetary Economics, 29(3), 341-369.

Leombroni, M., Vedolin, A., Venter, G., \& Whelan, P. (2019). Central bank communication and the yield curve. Available at SSRN 2873091.

Levant, J., \& Ma, J. (2017). A dynamic Nelson-Siegel yield curve model with Markov switching. Economic Modelling, 67, 73-87.

Li, K., Qin, Y., \& Wu, J. (2020). Recent housing affordability in urban China: A comprehensive overview. China Economic Review, 59, 101362.

Li, L. (1998). The China miracle: Development strategy and economic reform. Cato Journal, 18(1), 147.

Liao, L., Xiao, J. J., Zhang, W., \& Zhou, C. (2017). Financial literacy and risky asset holdings: evidence from China. Accounting \& Finance, 57(5), 1383-1415.

Lildholdt, P. M., Panigirtzoglou, N., \& Peacock, C. (2007). An affine macro-factor model of the UK yield curve.

Loo, M. K. L., \& Iqbal, B. A. (2019). Global competitiveness of BRICS and Canada: implications for business. Transnational Corporations Review, 11(2), 97-108.

Lyu, C., Wang, K., Zhang, F., \& Zhang, X. (2018). GDP management to meet or beat growth targets. Journal of Accounting and Economics, 66(1), 318-338

Maddison, A., \& Wu, H. (2006). China's economic performance: How fast has GDP grown? How big is it compared with the USA?. University of Queensland,(December).

Mankiw, N. G., \& Summers, L. H. (1984). Do long-term interest rates overreact to short-term interest rates? (No. w1345). National Bureau of Economic Research.

Marsh, L \& Cormier, D. (2002), Spline Models, S (2002).

Marty, W. (2017). The Flat Yield Curve Concept. In Fixed Income Analytics (pp. 17-102). Springer, Cham.

Mercurio, F. (2010). Modern LIBOR market models: using different curves for projecting rates and for discounting. International Journal of Theoretical and Applied Finance, 13(01), 113-137.

Mishkin, F. S. (1990). Yield curve (No. w3550). National Bureau of Economic Research.

Modigliani, F. (1944). Liquidity preference and the theory of interest and money. Econometrica, Journal of the Econometric Society, 45-88.

Møller, P. C., Mewis, J., \& Bonn, D. (2006). Yield stress and thixotropy: on the difficulty of measuring yield stresses in practice. Soft matter, 2(4), 274-283.

Moller. S, 2013. GDP growth and yield curvature. Finance Research Letters 11 (2014) 1-7.

Mönch, E. (2012). Term structure surprises: the predictive content of curvature, level, and slope. Journal of Applied Econometrics, 27(4), 574-602.

Nasruddin, A., \& Amin, N. (2013). Effects of cultivar, planting period, and fungicide usage on rice blast infection levels and crop yield. Journal of Agricultural Science, 5(1), 160.

Naughton, B. (2008). A political economy of China's economic transition. China's great economic transformation, 91-135.

Nelson, Charles R. and Andrew F. Siegel, 1987, "Parsimonious Modeling of Yield Curves,” Journal of Business, Vol. 60, 473-489.

Ng, S., Mabey, N., \& Gaventa, J. (2016). Pulling ahead on clean technology: China's 13th five year plan challenges Europe's low carbon competitiveness. Briefing Paper, E3G, London.

Nymand-Andersen, P. (2018). Yield curve modelling and a conceptual framework for estimating yield curves: evidence from the European Central Bank's yield curves (No. 27). ECB Statistics Paper.

Pagan, A., \& Robinson, T. (2014). Methods for assessing the impact of financial effects on business cycles in macroeconometric models. Journal of Macroeconomics, 41, 94-106.

Perkins, D. H., \& Rawski, T. G. (2008). Forecasting China's economic growth to 2025. China's great economic transformation, 829-86.

Piazzesi, M. (2010). Affine term structure models. In Handbook of financial econometrics: Tools and Techniques (pp. 691-766). North-Holland.

Piketty, T., Yang, L., \& Zucman, G. (2019). Capital accumulation, private property, and rising inequality in China, 1978-2015. American Economic Review, 109(7), 2469-96.

Pindado, F. (2008). La participación ciudadana es la vida de las ciudades. Barcelona: Ediciones del Serbal. 
Pinkovskiy, M., Sala-i-Martin, X., Frankel, J., Armstrong, A., Caselli, F., Chadha, J., \& den Haan, W. (2019). On the measuring and mis-measuring of Chinese growth.

Prasad, E. S., Rajan, R. G., \& Subramanian, A. (2007). Foreign capital and economic growth (No. w13619). National Bureau of Economic Research.

Rapach, D. E., Strauss, J. K., Tu, J., \& Zhou, G. (2019). Industry return predictability: A machine learning approach. The Journal of Financial Data Science, 1(3), 9-28.

Refet S.G., Brain S., and Jonathan H.W.(2007) show that the U.S. Treasury yield curve from 1961 to the present.

Reitano, R. R. (1992). Non-parallel yield curve shifts and immunization. Journal of portfolio management, 18(3), 36-43.

Roll, R., \& Ross, S. A. (1980). An empirical investigation of the arbitrage pricing theory. The Journal of Finance, 35(5), 1073-1103.

Rumbaugh, T., \& Blancher, N. (2004). China: international trade and WTO accession.

Sarig, O., \& Warga, A. (1989). Bond price data and bond market liquidity. Journal of Financial and Quantitative Analysis, 367-378.

Sarig, O., \& Warga, A. (1989). Some empirical estimates of the risk structure of interest rates. The Journal of Finance, 44(5), 1351-1360.

Schmitt, S. (2017). A parametric approach to estimate the green bond premium (Doctoral dissertation).

Shiller, R. J., \& McCulloch, J. H. (1990). The term structure of interest rates. Handbook of monetary economics, $1,627-722$.

Shilling, A. G. (2016). CHINA: LAND OF THE SETTING SUN.

Shumway, T. (2001). Forecasting bankruptcy more accurately: A simple hazard model. The journal of business, 74(1), 101-124.

Singleton, K. J., \& Umantsev, L. (2002). Pricing coupon-bond options and swaptions in affine term structure models. Mathematical Finance, 12(4), 427-446.

Song, X., \& He, Z. (2015). The Keqiang index: a new benchmark for China's development. Social Indicators Research, 123(3), 661-676.

Stoffberg, H. J., \& van Vuuren, G. (2016). Asset correlations in single factor credit risk models: an empirical investigation. Applied Economics, 48(17), 1602-1617.

Storn, R. (1996, June). On the usage of differential evolution for function optimization. In Proceedings of North American Fuzzy Information Processing (pp. 519-523). IEEE.

Svensson, L. E. (1994). Estimating and interpreting forward interest rates: Sweden 1992-1994 (No. w4871). National bureau of economic research.

Tanggaard, C. (1997). Nonparametric smoothing of yield curves. Review of Quantitative Finance and Accounting, 9(3), 251-267.

Taylor, C. (1993). To follow a rule. Bourdieu: critical perspectives, 6, 45-60.

Taylor, M. P. (1992). Modelling the yield curve. The Economic Journal, 102(412), 524-537.

Temel, J. W., \& Bond Market Association. (2001). The fundamentals of municipal bonds. John Wiley \& Sons.

The Department of China Central Depository and Clearing (2020), Zero-coupon bond yields, available at: https://cn.investing.com/rates-bonds/china-10-year-bond-yield, last accessed 10/11/2020

Thornton, D. L. (2012). Greenspan's conundrum and the Fed's ability to affect long-term yields. FRB of St. Louis Working Paper No.

Van Horne, J. C. (1980). The term structure: a test of the segmented markets hypothesis. Southern Economic Journal, 1129-1140.

Vasicek, O. (1977). An equilibrium characterization of the term structure. Journal of financial economics, 5(2), $177-188$

Vasicek, O. (1987). Probability of loss distribution. Technical report, KMV Corporation.

Vasicek, O. A., \& Fong, H. G. (1982). Term structure modeling using exponential splines. The Journal of Finance, 37(2), 339-348.

Vogel, R. M., Sieber, J., Archfield, S. A., Smith, M. P., Apse, C. D., \& Huber-Lee, A. (2007). Relations among storage, yield, and instream flow. Water Resources Research, 43(5).

Wang, J., Wu, C., \& Zhang, F. X. (2008). Liquidity, default, taxes, and yields on municipal bonds. Journal of Banking \& Finance, 32(6), 1133-1149.

Wang, X., Shi, R., \& Zhou, Y. (2020). Dynamics of urban sprawl and sustainable development in China. SocioEconomic Planning Sciences, 70, 100736.

Watkins, C. (1997). The term structure of interest rates and economic activity: An empirical critique. Mathematics and Computers in Simulation, 43(3-6), 487-493.

Wei, Y., Bai, L., Yang, K., \& Wei, G. (2005), Are industry-level indicators more helpful to forecast industrial stock volatility? Evidence from Chinese manufacturing purchasing managers index. Journal of Forecasting.

Weir, D. (2006). Timing the market: how to profit in the stock market using the yield curve, technical analysis, 
and cultural indicators (Vol. 235). John Wiley \& Sons.

Wen, Y., \& Wu, J. (2019). Withstanding the Great Recession Like China. The Manchester School, 87(2), 138-182.

Wright, J. H. (2006). The yield curve and predicting recessions.

Xiang, J., \& Zhu, X. (2013). A regime-switching Nelson-Siegel term structure model and interest rate forecasts. Journal of Financial Econometrics, 11(3), 522-555.

Xiao, K. (2019). Becoming global billionaires from mainland china: Theory and evidence. Available at SSRN 3465011.

Yallup, P. J. (2012). Models of the yield curve and the curvature of the implied forward rate function. Journal of Banking \& Finance, 36(1), 121-135.

Yawitz, J. B. (1977). The Relative Importance of Duration and Yield Volatility on Bond Price Volatility: Comment Journal of Money, Credit and Banking, 9(1), 97-102.

Yu J., Yongji G., Yihao Z., (2017) pointed out that GDP growth forecasts assume heightened importance for the Chinese government because China is the only major economy that sets a rigid target for annual GDP growth in the world.

Yu, H. (2017). Motivation behind China's 'One Belt, One Road'initiatives and establishment of the Asian infrastructure investment bank. Journal of Contemporary China, 26(105), 353-368.

Yu, W. C., \& Zivot, E. (2011). Forecasting the term structures of Treasury and corporate yields using dynamic Nelson-Siegel models. International Journal of Forecasting, 27(2), 579-591.

Zaloom, C. (2009). How to read the future: the yield curve, affect, and financial prediction. Public Culture, 21(2), 245-268.

Zhang, W. (2019). The China model view is factually false. Journal of Chinese Economic and Business Studies, 17(3), 287-311.

Zhuang C., Biao Y., Chang Yong H., Kwangwon A. (2018) offers a new approach to calibrating parameters of an agent-based model. 